University of Wollongong

Research Online

Faculty of Engineering and Information

Faculty of Engineering and Information

Sciences - Papers: Part B

Sciences

2019

Optimisation of life cycle performance of a double-pass photovoltaic thermal-solar air heater with heat pipes

Wenke Fan

University of Wollongong,wf303@uowmail.edu.au

Georgios Kokogiannakis

University of Wollongong, gkg@uow.edu.au

Zhenjun Ma

University of Wollongong, zhenjun@uow.edu.au

Follow this and additional works at: https://ro.uow.edu.au/eispapers1

Part of the Engineering Commons, and the Science and Technology Studies Commons

Research Online is the open access institutional repository for the University of Wollongong. For further information contact the UOW Library: research-pubs@uow.edu.au 


\title{
Optimisation of life cycle performance of a double-pass photovoltaic thermal- solar air heater with heat pipes
}

\author{
Abstract \\ A double pass photovoltaic thermal-solar air heater (PVT-SAH) system integrated with heat pipes was \\ developed with the aim of using it for applications that require high-temperature air. A dynamic model \\ was first developed and validated to predict the electrical and thermal performance of the PVT-SAH \\ system with heat pipes and inform an analysis of economic benefits. A life-cycle saving method was \\ employed, and an uncertainty analysis was included to investigate the economic performance of the \\ proposed system in comparison with the performance of a benchmark design. The optimal designs for \\ maximising electrical and thermal efficiencies of the new PVT-SAH system were obtained for several \\ system lengths through a multi-objective design optimisation strategy. The PVT-SAH systems with heat \\ pipes had higher capital construction costs than the benchmark designs but can still offer an annualised \\ life cycle saving that ranged from $A \$ 925$ to $A \$ 4606$ and a payback time between 5.7 and 16.8 years. The \\ PVT-SAH system with heat pipes was also found to deliver more efficient cooling effect to the PV panel \\ and improve the temperature uniformity of the PV panel. The temperature variation along the length of the \\ PV panel for the proposed system and for the benchmark design was $9.4^{\circ} \mathrm{C}$ and $21^{\circ} \mathrm{C}$ respectively. In \\ addition, the maximum thermal efficiency of the PVT-SAH with heat pipes was $69.2 \%$ compared to $61.7 \%$ \\ for benchmark design.

\section{Disciplines} \\ Engineering | Science and Technology Studies

\section{Publication Details} \\ Fan, W., Kokogiannakis, G. \& Ma, Z. (2019). Optimisation of life cycle performance of a double-pass \\ photovoltaic thermal-solar air heater with heat pipes. Renewable Energy, 138 90-105.
}


1 Optimisation of life cycle performance of a double-pass photovoltaic thermal-

2 solar air heater with heat pipes

\author{
Wenke Fan ${ }^{1, *}$, Georgios Kokogiannakis ${ }^{1}$, Zhenjun $\mathrm{Ma}^{1}$
}

${ }^{1}$ Sustainable Buildings Research Centre (SBRC), Faculty of Engineering and Information Science, University of Wollongong,
Wollongong, NSW, 2522, Australia
*Corresponding author
$*+61406144431$, wf303@ uowmail.edu.au

\title{
Abstract
}

A double pass photovoltaic thermal-solar air heater (PVT-SAH) system integrated with heat pipes was developed with the aim of using it for applications that require high-temperature air. A dynamic model was first developed and validated to predict the electrical and thermal performance of the PVT-SAH system with heat pipes and inform an analysis of economic benefits. A life-cycle saving method was employed, and an uncertainty analysis was included to investigate the economic performance of the proposed system in comparison with the performance of a benchmark design. The optimal designs for maximising electrical and thermal efficiencies of the new PVT-SAH system were obtained for several system lengths through a multi-objective design optimisation strategy. The PVTSAH systems with heat pipes had higher capital construction costs than the benchmark designs but can still offer an annualised life cycle saving that ranged from $\mathrm{A} \$ 925$ to $\mathrm{A} \$ 4606$ and a payback time between 5.7 and 16.8 years. The PVT-SAH system with heat pipes was also found to deliver more efficient cooling effect to the PV panel and improve the temperature uniformity of the PV panel. The temperature variation along the length of the PV panel for the proposed system and for the benchmark design was $9.4{ }^{\circ} \mathrm{C}$ and $21{ }^{\circ} \mathrm{C}$ respectively. In addition, the maximum thermal efficiency of the PVT-SAH with heat pipes was $69.2 \%$ compared to $61.7 \%$ for benchmark design.

Keywords: Photovoltaic thermal-solar air heater; Heat pipes; Model development; Life cycle saving method; Uncertainty analysis 


\begin{tabular}{|c|c|c|c|}
\hline$A$ & Surface areas of a control volume $\left(\mathrm{m}^{2}\right)$ & eva & Evaporator of the heat pipe \\
\hline$C$ & $\begin{array}{l}\text { Specific heat capacity }(k J /(k g \cdot K)) \text {; cost } \\
\text { (A } \$ \text { ) }\end{array}$ & co & Condenser of the heat pipe \\
\hline$M$ & $\begin{array}{l}\text { Mass per square meters }\left(\mathrm{kg} / \mathrm{m}^{2}\right) \text {; mass } \\
(\mathrm{kg}) \text {; month }\end{array}$ & $w f$ & Working fluid contained in the heat pipe \\
\hline$m$ & $\begin{array}{l}\text { Mass of flowing air in a control volume } \\
(\mathrm{kg})\end{array}$ & $a m b$ & Ambient air \\
\hline$T$ & Temperature $\left({ }^{\circ} \mathrm{C}\right)$ & channel2 & $\begin{array}{l}\text { Upper air channel of the PVT-SAH with } \\
\text { heat pipes }\end{array}$ \\
\hline$K$ & Thermal conductivity $(\mathrm{kJ} /(\mathrm{hr} \cdot \mathrm{m} \cdot \mathrm{K})$ & channel1 & $\begin{array}{l}\text { Lower air channel of the PVT-SAH with } \\
\text { heat pipes }\end{array}$ \\
\hline$R$ & Thermal resistance $(m \cdot K \cdot h r / k J)$ & insu & $\begin{array}{l}\text { Insulation layer between the upper and } \\
\text { lower air channel }\end{array}$ \\
\hline$H$ & Hight $(m)$ & $i$ & $\begin{array}{l}\text { the } i_{t h} \text { control volume along the length } \\
\text { of PVT-SAH }\end{array}$ \\
\hline$L$ & Length $(m)$ & $c S$ & $\begin{array}{l}\text { Contact areas between fins and bottom } \\
\text { plate }\end{array}$ \\
\hline$D$ & Diameter $(m)$ & bs & Backplate beneath the PV plate \\
\hline$W$ & Width $(m)$ & in & $\begin{array}{l}\text { Inside surface of the heat pipe; Inlet of } \\
\text { the PVT-SAH system }\end{array}$ \\
\hline Q & Energy $(k J)$ & out & $\begin{array}{l}\text { Outside surface of the heat pipe; Outlet } \\
\text { of the PVT-SAH system }\end{array}$ \\
\hline$t$ & Time step $(h r)$; Thickness $(m)$ & $h p$ & Heat pipe \\
\hline$h$ & Heat transfer coefficient $\left(\mathrm{kJ} /\left(h r \cdot m^{2} \cdot K\right)\right.$ & $g$ & Glass cover \\
\hline$\Delta x$ & $\begin{array}{l}\text { length of each control volume along the air } \\
\text { flow direction }(m)\end{array}$ & $b s$ & $\begin{array}{l}\text { Back sheet beneath the PV plate (heat } \\
\text { pipe type) }\end{array}$ \\
\hline$R e$ & Reynold number & $f_{2}$ & flowing air in the upper air channel \\
\hline$N u$ & Nusselt number & $f_{1}$ & flowing air in the lower channel \\
\hline $\operatorname{Pr}$ & Prandtl number & fin & longitude fins \\
\hline$\rho$ & Density $\left(\mathrm{kg} / \mathrm{m}^{3}\right)$ & $b$ & Bottom plate \\
\hline \multicolumn{2}{|c|}{ Subscript } & $p$ & Absorber plate \\
\hline$P V$ & PV plate & $\begin{array}{l}p v t \\
-s a h\end{array}$ & PVT-SAH systems \\
\hline$S A H$ & Solar air heater & & \\
\hline
\end{tabular}

\section{Introduction}

27 In the past decades, significant efforts have been made to develop technologies to improve the thermal and electrical

28 performance of photovoltaic thermal (PVT) collectors and solar air heaters (SAH). Examples of the technologies

29 reported in the literature for the heat transfer enhancement and improved energy conservation include the use of

30 transparent insulation on the top of the system [1,2], double or multiple air channels [3-5], selective coating 
materials [6,7], artificial surface roughness [8-10] and attaching fins in air channels [11-14]. However, limited research has been done on the potential use of heat pipes for enhancing the electrical and thermal performance of PVT systems. Heat pipes have been proven to be an efficient heat transfer technology which utilises the phase changes (evaporation and condensation) of the contained working fluid to transport a large amount of heat to a long distance. The thermal-diode feature of the heat pipes which allows the heat flow through only one direction makes it attractive to be incorporated into the PVT collectors. Furthermore, although many of the existing PVT enhancement technologies can reduce the overheating of PV panels, the temperatures of the PV cells are often subject to a significant variation along the length of the system. The non-uniform temperature distribution on the PV panel will adversely affect the electricity generation because the PV cells are connected in series [15, 16]. A careful selection of appropriate combinations of heat pipe characteristics (i.e. inner fluid, pitch distance, filling ratio, pressure and wick structure) can effectively reduce the non-uniformity of the temperature distribution on the PV panels [17]. Because of their exceptional thermal management performance, heat pipes have been widely applied in the electronics industry [18], and in space and terrestrial technologies [19]. However, the integration of heat pipes into the PVT systems has only been reported in few papers. For instance, Gang et al. [20] developed a dynamic model for a water-based heat pipe PVT system and validated the model with experimental data. Wu et al. [21] investigated the effect of the mass flow rate of a water-based heat pipe PVT collector on the temperature uniformity of a PV panel. Hu et al. [17] reported that the thermal performance of a wire-meshed heat pipe PVT was less sensitive to the inclination angle than the PVT with wickless heat pipes and the maximum thermal efficiency of these two heat pipe PVT types were $52.8 \%$ and $51.5 \%$ respectively. The above existing studies were performed based on water-based heat pipe PVT systems. As the air-based PVT systems are increasingly used for the hightemperature applications (for example to regenerate a solid desiccant wheel [22]), it is also desirable to develop an air-based PVT system that makes full use of the advantages of heat pipes and provides high outlet air temperatures. 
For this purpose, a new design of a hybrid PVT-SAH system with double air pass that is integrated with heat pipes is proposed and is shown in Figure 1. The proposed system can generate output air of relatively high temperature which can be potentially used to regenerate the desiccant in a desiccant wheel for summer cooling applications. The upper channel of the system is formed by a SAH which is used to further increase the outlet air temperature from the heat pipe PVT.

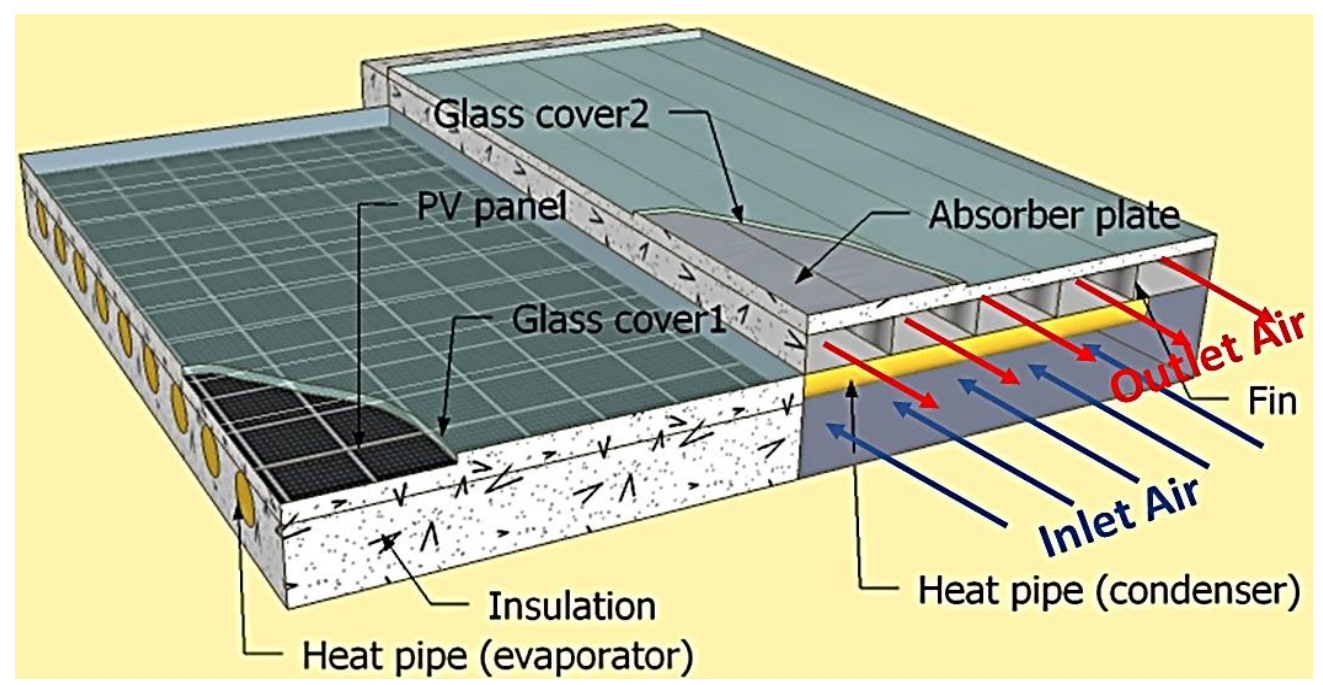

Figure 1. Illustration of the hybrid double pass PVT-SAH system integrated with heat pipes - New design [23].

Besides the thermal and electrical efficiency, economic factors for the proposed PVT-SAH system are another important consideration to be taken into account while evaluating the performance of such systems. Chow [24] pointed out that the lack of economic viability is one of the main bottlenecks for the commercial promotion of PVT products. Most of the previous studies focused on the thermal and electrical performance of the PVT or SAH systems with just a limited number of studies integrating a cost analysis in the performance assessments of these systems. For instance, Agrawal and Tiwari [25] performed a life cycle analysis of building integrated photovoltaic/thermal systems (BIPVT) with regard to energy and economic performance for different PV technologies. It was found that the mono-crystalline BIPVT system performed better than the amorphous silicon BIPVT system in terms of energy and exergy efficiencies, however, the later one was more economically feasible. A similar study conducted by Raman and Tiwari [26] examined the cost/kWh of the thermal and electrical outputs 
from a PVT system for different Indian climate conditions. Kumar and Tiwari [27] investigated and compared the

71 performance of PVT assisted active solar stills with a conventional passive solar still using life cycle cost analysis.

72 Considering the influences of various parameters such as interest rate, the lifespan of the system and maintenance

73 cost, it was observed that the cost of distilled water produced by the PVT assisted solar still system was higher than

74 the conventional system. The PVT solar still system was estimated to have 3.3 to 23.9 years of payback while the

75 conventional one varied from 1.1 to 6.2 years based on different selling prices of distilled water.

76 The economic analysis of the above studies was performed under the assumptions that the initial investment cost,

77 the cost of fuels, the values of the financial parameters and climate conditions were constant. However, in practice,

78 the values of the above-mentioned cost parameters can significantly vary against the locations and time. To make

79 the results of the economic analysis more generic and useful, an uncertainty analysis needs to be considered to

80 quantify the risks associated with the economic performance caused by the uncertainty of the above factors.

81 To bridge the knowledge gaps mentioned above, this paper presents a performance appraisal for a new design of a

82 PVT-SAH system with integrated heat pipes. The modelling and model validation analyses of the proposed system

83 are described and the electrical/thermal as well as the economic performance of the proposed system are presented.

84 A detailed analysis of the uncertainties with regard to the economic performance of the system is undertaken. In addition, a benchmark design of a PVT-SAH system (Figure 2) is used for comparison purposes. 


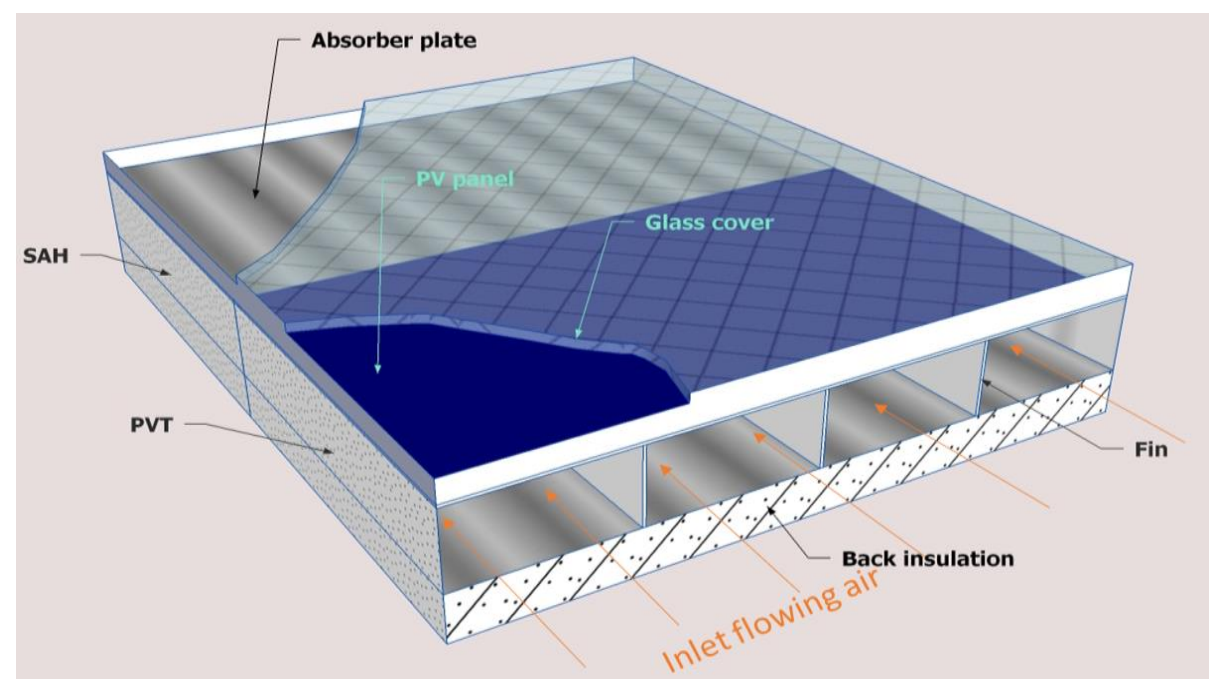

Figure 2. Illustration of the hybrid PVT-SAH system with fins - Benchmark design [28].

\section{System description and research method}

\subsection{Double pass PVT-SAH system integrated with heat pipes}

The proposed double pass PVT-SAH system integrated with heat pipes can be decomposed into two subsystems: a PVT module with heat pipes and a SAH module as shown in Figure 3 (a). The PVT module consists of the glass cover, PV panel, back plate, heat pipes and a lower air channel. The SAH module includes the glass cover, absorber plate, an upper air channel and the inserted longitudinal fins. The evaporators of the heat pipes are arranged beneath the back sheet of the PV panel to extract the thermal energy which is then transferred to the condenser section of the heat pipe via the phase changes of the inner fluid. The condensers of the heat pipes are inserted into the lower air channel and transfer the heat to the cross-flowing air. When operating, the ambient air from the outside is first circulated to the lower channel where it is heated up by the heat generated from the heat pipes. The heated air is then circulated to the upper channel where the absorber plate of the SAH will further increase the air temperature (Figure 3 (b)). The PVT and SAH modules are linked by a connection layer (using insulation and adhesive materials) and the heat exchanges between upper and lower channels could also occur through the same connection layer. 


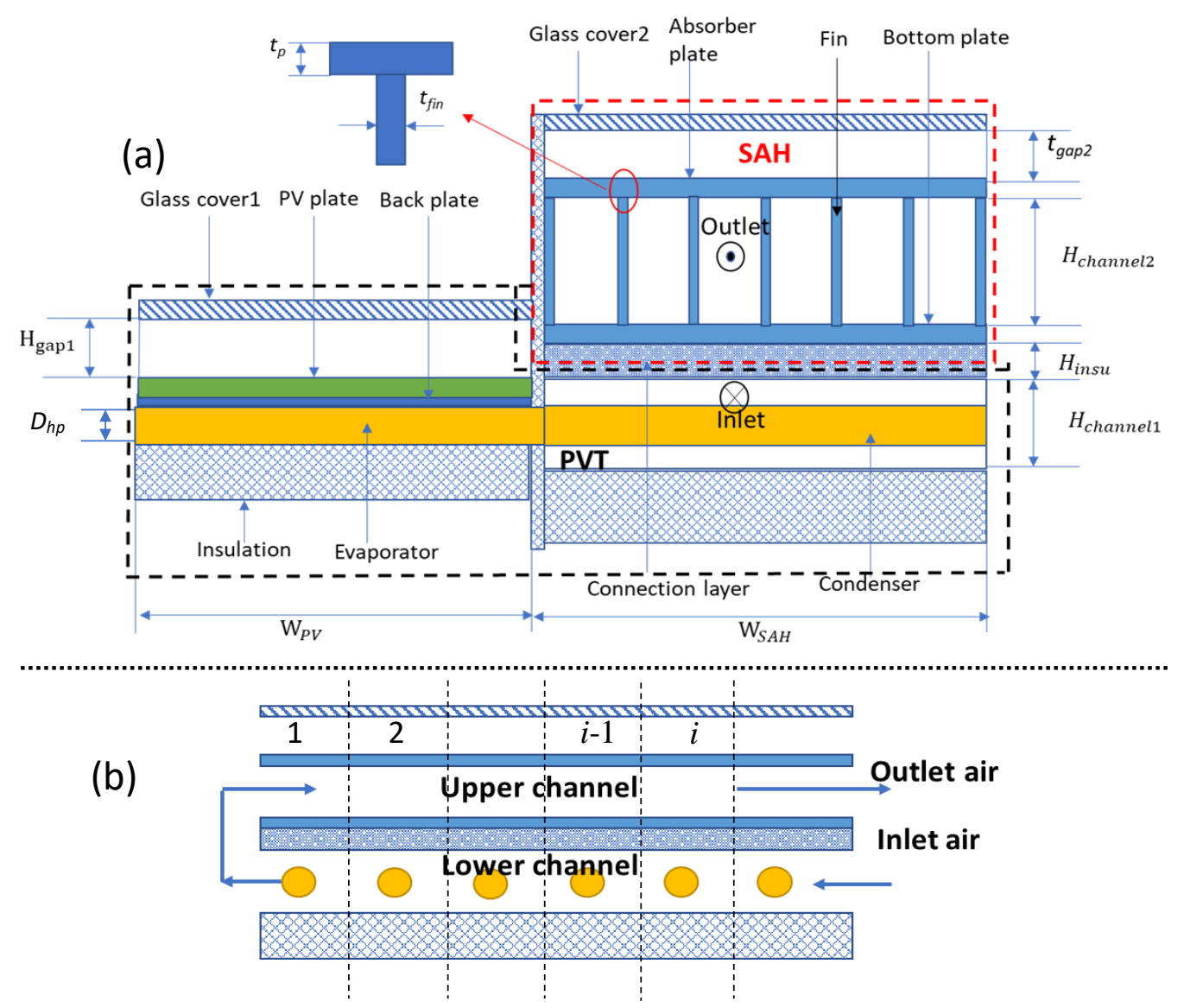

Figure 3. Section-view of (a) the hybrid PVT-SAH integrated with heat pipes; (b) the upper and lower air flow channels [23].

\subsection{Outline of the research method}

The performance of this system was evaluated based on the procedures illustrated in Figure 4, by following four main steps:

- In the first step, a dynamic energy performance model of the double pass PVT-SAH system integrated with heat pipes is developed and validated.

- In the second step, a multi-objective design optimization strategy is employed to obtain a set of Pareto integrated and the benchmark PVT-SAH system will be evaluated and compared under the same conditions.

- In Step 3, three representative candidate designs are chosen from the previously obtained Pareto Fronts to 
represent the lowest, middle and highest-level priority for maximising the thermal energy outputs against the electricity outputs. Based on the identified cost parameters and the candidate designs considered, the life cycle cost saving method is utilised to evaluate the economic performance of the heat pipe integrated and the benchmark PVT-SAH systems.

- Finally, in Step 4, the uncertainties in the economic performance of the new heat pipe integrated and benchmark PVT-SAH systems are analysed based on the uncertainties in the cost parameters for the construction and operation of the system.

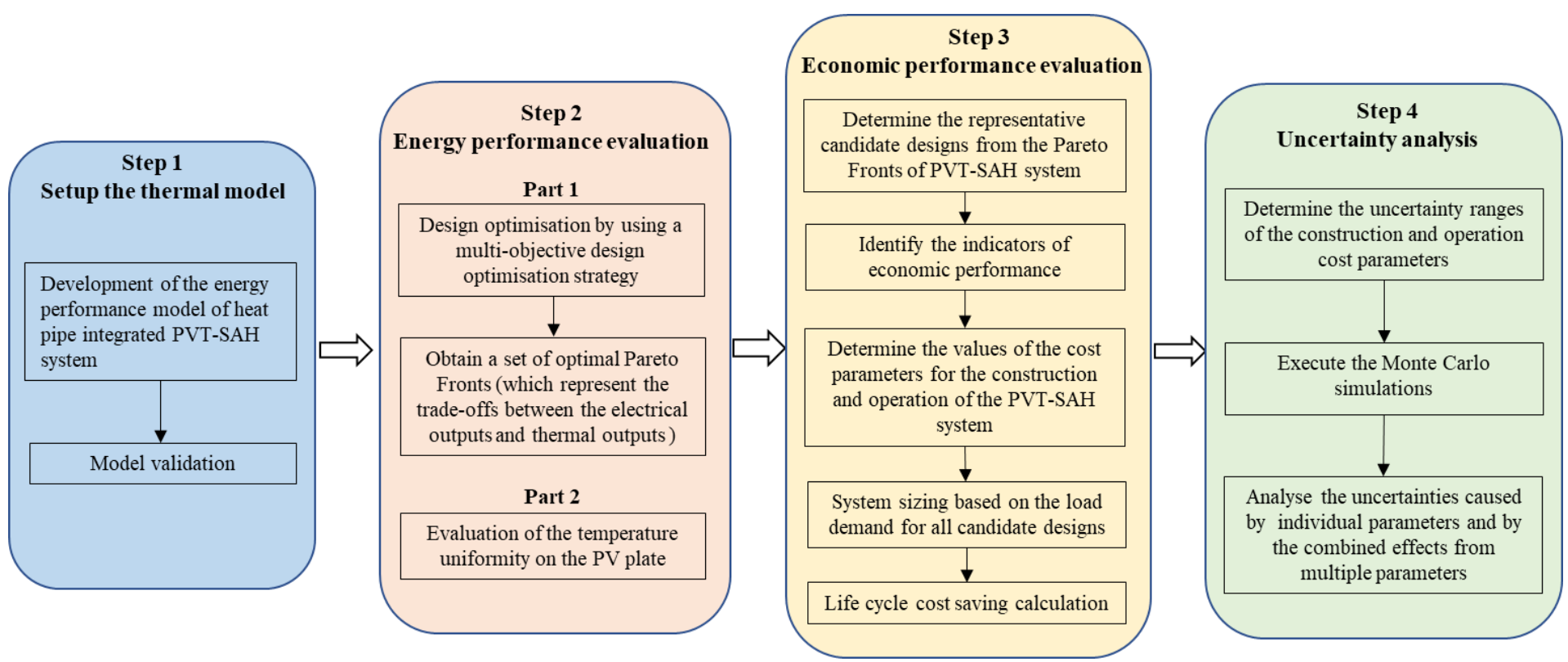

Figure 4. Outline of the research method employed.

\section{Dynamic modelling of PVT-SAH systems}

A dynamic model of a PVT-SAH system with integrated heat pipes was first developed for performance prediction.

As the design of heat pipe integrated PVT-SAH systems can be considered the combination of a heat-pipe PVT module and a finned SAH module (see Figure 3 (a)), the prediction model of the whole system can be developed by coupling a model of a standalone heat pipe PVT having a single air pass [20] with a model of a finned SAH [29]. The nature of the coupling was to consider the heat exchanges between the upper channel and lower channel through the connection layer and to consider the heat and mass transfer from the outlet of the heat-pipe PVT to the 
inlet of the SAH. The inlet air temperature of the lower channel (PVT) was equal to the ambient air temperature and its outlet temperature was assigned to be the inlet air temperature of the upper channel (SAH). In addition to the modifications for the coupling of the two models, the model of the PVT module [20] was modified by developing a new energy balance equation for the inner fluid of the heat pipe which enabled to consider the characteristics of the inner fluid (i.e. thermo-physical properties and liquid filling ratio) into the model calculation. and the flowing air node in the heat-pipe PVT [20] are as follows:

The energy balance equation for the bottom plate of SAH is:

$$
\begin{aligned}
A_{b, i} C_{b} M_{b} \partial T_{b, i} / \partial t & \\
& =A_{c s} K_{f i n}\left(T_{f i n, i}-T_{b, i}\right) /\left(H_{f i n} / 2\right) \\
& +A_{b, i} h_{r, p-b}\left(T_{p, i}-T_{b, i}\right)-A_{b, i} h_{c, b-f_{2}}\left(T_{b, i}-T_{f_{2}, i}\right) \\
& -A_{i}\left(T_{b, i}-T_{f 1, i}\right) / R_{b, f_{1}}
\end{aligned}
$$

The left-hand side of the equation includes the differential change of the accumulated energy stored in the control volume of the bottom plate, and the right-hand side terms represent the conduction heat transfer from fins to the bottom plate, radiation heat transfer from the absorber plate to the bottom plate, convective heat transfer from the flowing air in the upper channel to the bottom plate and the combined heat transfer from the bottom plate to the flowing air in the lower channel. The equations of the convection heat transfer coefficient $h_{c, b-f_{2}}$ and radiation heat transfer coefficient $h_{r, p-b}$ can be found in the study [29].

144 The energy balance equation for the flowing air node in the lower channel is as follows:

$$
\begin{aligned}
C_{f_{1}} \rho_{f_{1}} \Delta x\left(L_{S A H} H_{\text {channel } 2}\right) \partial T_{f 1, i} / \partial t+C_{f_{1}} m_{f_{1}} \Delta x \partial T_{f_{1}, i} / \partial x \\
=\pi D_{\text {co,out }} L_{c o} h_{c, c o-f_{1}}\left(T_{c o, i}-T_{f_{1}, i}\right) \\
\quad+A_{b, i}\left(T_{b, i}-T_{f_{1}, i}\right) / R_{b, f_{1}}+A_{i}\left(T_{a m b}-T_{f_{1}, i}\right) / R_{f_{1}, a m b}
\end{aligned}
$$

145 The left-hand side terms in Eq. (2) represent differential change of the energy storage in the control volume for the 
flowing air node and the temperature gradient along the flow direction, while the right-hand side terms are the convection heat transfer from the condenser to the flowing air, the convection heat transfer from the duct air to the bottom plate of the SAH, and the convection and conduction heat transfer from the flowing air in the channel to

149 the surrounding ambient air. The convection heat transfer coefficient $h_{c, c o-f_{1}}$ which is used to evaluate the heat transfer between the flowing air and the outside surface of the heat pipes is given by:

$$
h_{c, c o-f_{1}}=\frac{N u_{c o-f_{1}} \cdot K \cdot 3.6}{D_{c o, o u t}}
$$

where $N u_{c o-f_{1}}$ (Eq. (4))is provided in the study [30]:

$$
N u_{c o-f_{1}}=0.3+\frac{0.62 \cdot R e^{1 / 2} \cdot \operatorname{Pr}^{1 / 3}}{\left[1+(0.4 / P r)^{2 / 3}\right]^{1 / 4}} \cdot\left[1+\left(\frac{R e}{282000}\right)^{5 / 8}\right]^{4 / 5}
$$

in which the Reynold number $(R e)$ is evaluated by using the outside diameter of the heat pipe $\left(d_{\text {out }}\right)$ as the characteristic length.

One of the modifications made to the source model [20] is adding a newly developed energy balance equation for the inner working fluid of the heat pipe and the equation is expressed in Eq. (5):

$$
\begin{aligned}
C_{w f} M_{w f} \frac{\partial T_{w f, i}}{\partial t} & \\
& =\pi D_{e v a, i n} L_{e v} h_{e v a}\left(T_{e v a, i}-T_{w f, i}\right) \\
& +\pi D_{c o, i n} L_{c o} h_{c o}\left(T_{w f, i}-T_{c o, i}\right)
\end{aligned}
$$

The left-hand side term represents the heat storage rate of the working fluid, while the terms on the right-hand side include the heat exchange between the evaporator shell and the working fluid, and the condensation heat transfer between the working fluid and condenser. The condensation heat transfer coefficient $\left(h_{c o}\right)$ and evaporation heat transfer coefficient $\left(h_{\text {eva }}\right)$ can be found in the study [31].

The energy balance at the evaporator's finite volume is given by Eq. (6): 


$$
\begin{aligned}
C_{e v a} M_{e v a} \frac{\partial T_{e v a, i}}{\partial t} & \\
\quad & \pi D_{e v a, i n} L_{e v a} h_{e v a}\left(T_{w f, i}-T_{e v a, i}\right) \\
& +\left(T_{b c, i}-T_{e v a, i}\right) / R_{b c, e v a}
\end{aligned}
$$

The right-hand side terms include the heat conduction flux between the inside surface of the evaporator and the working fluid, and the conduction flux between the back plate and the outside surface of the evaporator.

Eq. (7) is used for the energy balance in the condenser:

$$
C_{c o} M_{c o} \frac{\partial T_{c o, i}}{\partial t}=\pi D_{c o, i n} L_{c o} h_{c o}\left(T_{w f, i}-T_{c o, i}\right)+\pi D_{c o, o u t} L_{c o} h_{f_{1}}\left(T_{f_{1}, i}-T_{c o, i}\right)
$$

The right-hand side includes the absorbed heat by the condenser through the condensation process of the gas working fluid and the convection heat exchange between the duct air in the lower channel and condenser surface.

\section{Energy performance evaluation}

\subsection{Annual useful thermal energy efficiency $\left(\boldsymbol{\eta}_{t h-y e a r}\right)$}

In the context of this work, the useful thermal energy is defined as the thermal energy generated by the PVT-SAH systems when the outlet air temperature is greater than $60^{\circ} \mathrm{C}$ so that it can be effectively used for a desiccant regeneration process. In order to reduce the computational cost for optimization, one typical day was selected to represent the weather conditions of the given month and the total output of the useful thermal energy in this month was determined by multiplying the useful thermal energy output of the typical day with the number of days of this month. The typical day was determined based on the specification provided by "Climate Design Data 2009 ASHRAE handbook" [32]. The annual output of the useful thermal energy is the sum of the monthly generation of the useful thermal energy.

The expression used to calculate the monthly useful thermal energy is shown below: 


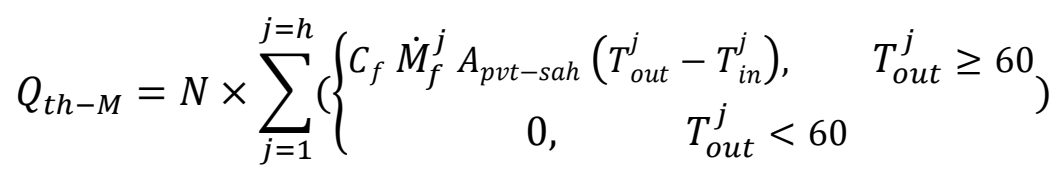

178 where $N$ is the number of days in the month, $\dot{M}_{f}$ is the air mass flow rate $(\mathrm{kg} / \mathrm{hr}), \mathrm{h}$ and $\mathrm{j}$ are the number of hours 179 and the $j_{t h}$ hour of the typical day.

180 Based on the yearly useful thermal energy output, the yearly useful thermal efficiency can be calculated:

$$
\eta_{\text {th-year }}=\frac{Q_{\text {th-year }}}{I_{\text {year }} \times A_{\text {pvt-sah }}}
$$

181

where $I_{\text {year }}$ is the yearly global solar radiation per square meters on the surface of the PVT-SAH system $\left(\mathrm{kJ} / \mathrm{m}^{2}\right)$.

\subsection{Annual net electrical efficiency $\left(\boldsymbol{\eta}_{\text {ele-year }}\right)$}

Similarly, the annual electricity generation $\left(Q_{\text {ele-year }}\right)$ by the PV system can be obtained by summing up the monthly electricity outputs of the year.

The monthly electricity generation is calculated as below:

$$
Q_{e l e-M}=N \times \sum_{j=1}^{j=h} I_{t}^{j} \alpha_{p v} A_{p v} \eta_{p v}^{j}
$$

where $I_{t}^{j}$ is the total amount of the solar radiation exposed to the unit area of the PV system per hour $\left(\mathrm{kJ} / \mathrm{hr} \cdot \mathrm{m}^{2}\right)$, and $\eta_{p v}^{j}$ is the electrical efficiency which is calculated using Eq. (11) [33].

$$
\eta_{p v}^{j}=\eta_{\text {ref }}\left(1-0.0045\left[T_{p v}^{j}-25^{\circ} \mathrm{C}\right]\right)
$$

The PVT-SAH system uses a mechanical fan to drive the air flow and the annual electricity consumed by the fan is given by Eq. (12) [12].

$$
Q_{\text {fan-year }}^{j}=\sum_{M=J a n}^{M=D e c}\left(N \times \sum_{j=1}^{j=h}\left(\Delta p^{j} \dot{M}_{f}^{j}\right) /\left(\eta_{\text {fan }} \rho_{f}\right)\right)
$$

where $\rho_{f}$ is the air density $\left(\mathrm{kg} / \mathrm{m}^{3}\right), \eta_{f a n}$ is the combined efficiency of the fan and motor (\%), typically ranging 
from 60 to $70 \%$ [34-36] and in this study the fan efficiency was assumed to be $63 \%$. The pressure drops $\Delta p$ in the

193 air channel is determined by Eq. (13).

$$
\Delta p^{j}=f r \frac{L_{p v t-s a h}}{D_{h}} \frac{\rho_{f}\left(u^{j}\right)^{2}}{2}
$$

where $L_{p v t-s a h}$ is the total length of the PVT-SAH system $(m)$, and $f r$ is the friction coefficient in the air channels. For the benchmark PVT-SAH and the upper channel of the heat pipe integrated PVT-SAH, the $f r$ can be obtained from a Moody chart [37] while the $f r$ for the lower channel of the heat-pipe PVT-SAH can be found in [38].

Considering the fan consumption, the annual net electrical efficiency is given by:

$$
\eta_{\text {net-ele-year }}=\frac{Q_{\text {ele-year }}-Q_{\text {fan-year }}}{I_{\text {year }} \times A_{\text {pvt-sah }}}
$$

In this study, the useful thermal efficiency and net electrical efficiency are evaluated for the optimal design of the PVT-SAH system. A multi-objective design optimisation strategy using a genetic algorithm was previously presented for this type of systems [28] and it is utilised to obtain the optimal design of the PVT-SAH system. The design parameters and the parameter constraints for the optimisation of the PVT-SAH with heat pipes were specified in [23].

\section{Economic performance evaluation}

The economic performance of the heat pipe integrated PVT-SAH and the benchmark PVT-SAH are evaluated based on the assumption that the generations of useful thermal energy and electricity are respectively used to drive the desiccant cooling system and reduce the household electricity demand. The following three economic indicators are used in this study: (1) Capital cost per kilowatt thermal capacity (CCKT); (2) Annualised life-cycle cost saving (ALCS) and (3) Payback Time (PBT).

\section{- Capital cost per kilowatt thermal capacity (CCKT)}

The thermal capacity of the PVT-SAH system is $E_{t h}(\mathrm{~kW})$ and the capital cost for the manufacture is $C_{c a}$, the 
CCKT is assumed to be:

$$
\mathrm{CCKT}=\frac{C_{c a}}{E_{t h}}
$$

213 The annualised life-cycle saving (ALCS) which gives an equal cost saving over the life cycle that is equivalent to

214 the varying series of annual savings is determined by the Eq. (16) [39]:

$$
A L C S=\frac{L C S}{P W F\left(N_{L}, 0, d\right)}
$$

215 where LCS is the life cycle cost saving for running the PVT-SAH system and PWF $\left(N_{L}, 0, \mathrm{~d}\right)$ is the present worth 216 factor.

\section{- Payback time (PBT)}

218 Payback time (PBT) is defined as the time needed for the cumulative fuel cost savings in the present worth to equal to the capital cost of the PVT-SAH systems and is determined by Eq. (17) [39]:

$$
\mathrm{PBT}=\ln \left[\frac{C_{c a}(e-d)}{S_{f u e l, 1}}+1\right] / \ln \left(\frac{1+e}{1+d}\right)
$$

220 The life cycle savings method is used to evaluate the economic performance of the PVT-SAH systems for driving

221 a desiccant cooling system. A general expression to show the present-worth cost saving in the $j_{t h}$ year of the life 222 cycle is presented in Eq.(18).

$$
\begin{aligned}
& \text { PW_S } \text { Total,j }= \\
& \left\{\begin{array}{c}
-C_{\text {down }}, 0 \\
\text { PW_S } S_{\text {fuel,j }}-P_{-} W_{\text {loan }, j}-P W_{-} C_{m, j}-P W_{-} C_{o, j}, \quad 1 \leq j \leq N_{L}-1 \\
P W_{-} S_{\text {fuel,j }}-P W_{-} C_{\text {loan }, j}-P W_{-} C_{m, j}-P W_{-} C_{o, j}+P W_{-} S_{s a}, \quad j=N_{L}
\end{array}\right.
\end{aligned}
$$

223 Summing up the cost saving of each year, the life cycle saving (LCS) can be obtained as:

$$
\mathrm{LCS}=\sum_{j=0}^{j=N_{L}} \mathrm{PW}_{-} \mathrm{S}_{\text {Total, }}
$$

224 Eq. (18) was developed based on the following assumptions:

225 The initial capital cost $\left(C_{c a}\right)$ is supported by $10 \%$ down payment $\left(\mathrm{C}_{\mathrm{down}}\right)$ and the remaining $90 \%$ bank mortgage 
is paid by a series of equal payment $\left(P_{l o a n}\right)$ each year with the loan payment period equal to the life cycle period.

227 At the beginning of the life cycle $(\mathrm{j}=0)$ when the PVT-SAH system has not started working, only a down payment is introduced, while in the last year of the life cycle $\left(\mathrm{j}=N_{L}\right)$, the salvage value (PW_ $\left.S_{s a}\right)$ of the PVT-SAH system is taken into account. The present-worth cost saving in the $j_{t h}$ year is the subtraction of the loan payment $\left(\mathrm{PW} \_C_{l o a n, j}\right)$, maintenance cost $\left(\mathrm{PW} \_C_{m, j}\right)$ and operation cost $\left(\mathrm{PW}_{-} C_{o, j}\right)$ from the fuel saving $\left(\mathrm{PW} \_S_{f u e l, j}\right)$.

The capital cost incurred includes the investment costs of buying the materials and components used to construct the PVT-SAH systems and the cost related to system fabrication and installation which is given by Eq (20).

$$
\begin{gathered}
C_{c a}=\left(C_{g}+C_{P V}+C_{b s}+C_{\text {insu }}+C_{p}+C_{b}+C_{f i n}+C_{\text {sele }}+C_{u s}+C_{l s}\right. \\
\left.+C_{h p}\right)+C_{\text {fa\&ins }}
\end{gathered}
$$

233 The cost of components contained in Eq. (20) is estimated by multiplying the areas or weight of the given component

234 by its unit price. Except for the glass covers and the copper-made heat pipes, the other structural components are

235 fabricated with steel sheets and the cost of these components are evaluated by their weights. The weights of the above-mentioned components can be determined from the design parameters of the heat pipe PVT-SAH system. The cost of PV panels $\left(C_{P V}\right)$ and solar selective films $\left(C_{\text {sele }}\right)$ is priced by electrical capacity and dimensional areas, respectively. The cost associated with the fabrication and installation $C_{\text {fa\&ins }}$ in Australia is assumed to be 30\% [40] of the total cost of buying the materials and components for PVT-SAH systems. The methods to calculate the present 240 worth of loan payment $\left(P W_{-} P_{l o a n, j}\right)$, operation cost $\left(P W_{-} C_{o, j}\right)$, maintenance cost $\left(P W_{C_{m, j}}\right)$, fuel cost saving $241\left(P W_{\text {fuel_saving }}\right)$ and the salvage value $\left(P W_{S_{s a}}\right)$ can be found in the literature, for example in Duffie and Beckman [39], 242 and are not therefore repeated here.

\section{$243 \quad 6$ Results and Discussions}

\section{$244 \quad 6.1 \quad$ Testing conditions}

245 The energy and economic performance of the heat pipe integrated PVT-SAH system is evaluated under the climate conditions of Darwin City, Australia, where the climate is humid and hot, and cooling is needed throughout the 
year. The hot and humid climate provides great potentials for applying the proposed PVT-SAH systems to the desiccant cooling process. The typical-day weather conditions of each month are presented in Figure 5.

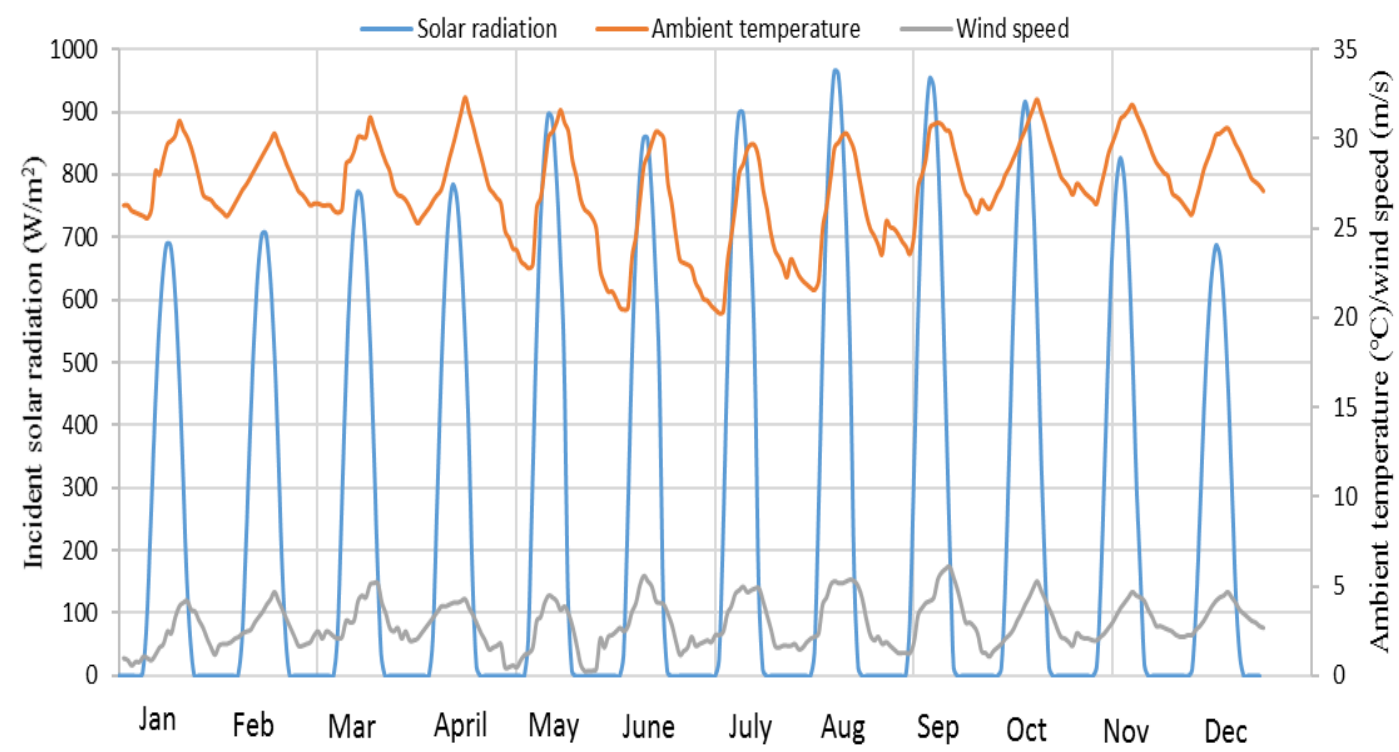

Figure 5. Typical-day weather conditions of each month in Darwin, Australia, based on values supplied by the stats file of [32].

The performance of the heat pipe PVT-SAH system is evaluated for three levels of system lengths, i.e. short (4 meters), medium (10 meters) and long (16 meters). The values of the construction and operation costs used for economic analysis as well as the reference of the values are summarised in Table 1. The life cycle of the PVT-SAH system was assumed to be 20 years which is within the reasonable lifespan of the solar thermal systems that were used in other studies [25, 27]. It should be noted that there are uncertainties with regard to the lifespan of the system, in particular the failures of a single or multiple components of the PVT-SAH system could reduce its electrical and thermal performance and shorten its lifespan. For example, occurrences of power failure, control problems, servicing and summer shutdown could cause no-flow conditions in the air channel of the PVT-SAH, leading to high stagnation temperatures under the conditions of high radiation. The high stagnation temperatures could result in irreversible damages to PV cells and solar spectrally selective coatings (or paints) on the absorber plate and affect the solar optical properties of the insulation glazing. Besides, corrosion and hail damages as well as the moisture 
condensation under the glass cover are other important factors that influence the lifespan and long-term performance of the PVT-SAH system. Such uncertainties however were not considered in this study.

264 The future development of new photovoltaic technologies could have increased electricity conversion efficiency 265 and reduced cost for practical applications [41]. As the high-efficient and low-cost photovoltaic systems could 266 generate more electricity, less amount of solar radiation will be converted into thermal energy which reduces the 267 need for developing PVT systems for cooling the PV cells. On the other hand, it could be economically feasible to 268 directly use the low-cost electricity generated from the PV systems to power heat pumps for space heating and cooling, which makes the application of thermal energy from the PVT-SAH for the desiccant cooling process less attractive.

Table 1. Construction and operation cost parameters used for the economic analysis of the PVT-SAH systems.

\begin{tabular}{|c|c|c|}
\hline Construction cost parameters & Unit & Value \\
\hline Glass cover (thickness of $3 \mathrm{~mm}$ ) & $\mathrm{A} \$ / \mathrm{kg}$ & $9[42]$ \\
\hline Steel sheet & $\mathrm{A} \$ / \mathrm{kg}$ & $4[43]$ \\
\hline Heat pipe & $\mathrm{A} \$ / \mathrm{kg}$ & $9[44]$ \\
\hline PV panel & $\mathrm{A} \$ / \mathrm{m}^{2}$ & $250[45]$ \\
\hline Insulation $\left(\mathrm{R}=4.0 \mathrm{~m}^{2} \cdot \mathrm{K} / \mathrm{W}\right)$ & $\mathrm{A} \$ / \mathrm{m}^{2}$ & $8[46]$ \\
\hline Solar selective coating film & $\mathrm{A} \$ / \mathrm{m}^{2}$ & $30[44]$ \\
\hline Fabrication and installation cost & $\%$ of materials and components cost & $130[40]$ \\
\hline Operation cost parameters & Unit & Value \\
\hline Average inflation rate & $\%$ & $2.9[40]$ \\
\hline Interest (discount) rate & $\%$ & $6[40]$ \\
\hline Escalation rate of the electricity price & $\%$ & $3[40]$ \\
\hline Average electricity price & $\mathrm{A} \$ / \mathrm{kWh}$ & $0.22[47]$ \\
\hline Annual maintenance cost & $\%$ of the capital cost & $1.25[40]$ \\
\hline
\end{tabular}

272 The benchmark PVT-SAH used for performance comparison (Figure 6) is composed of a PVT and SAH with the

273 SAH linked behind the PVT in series. The longitudinal fins are evenly inserted into the air channels to increase the

274 heat transfer areas between the flowing air and the surface of the air channels. The purpose of linking the SAH

275 behind the PVT is to reduce the operating temperature of the PV panel and further increase the outlet air temperature

276 so that the thermal energy captured can be used to drive a desiccant cooling process effectively. 


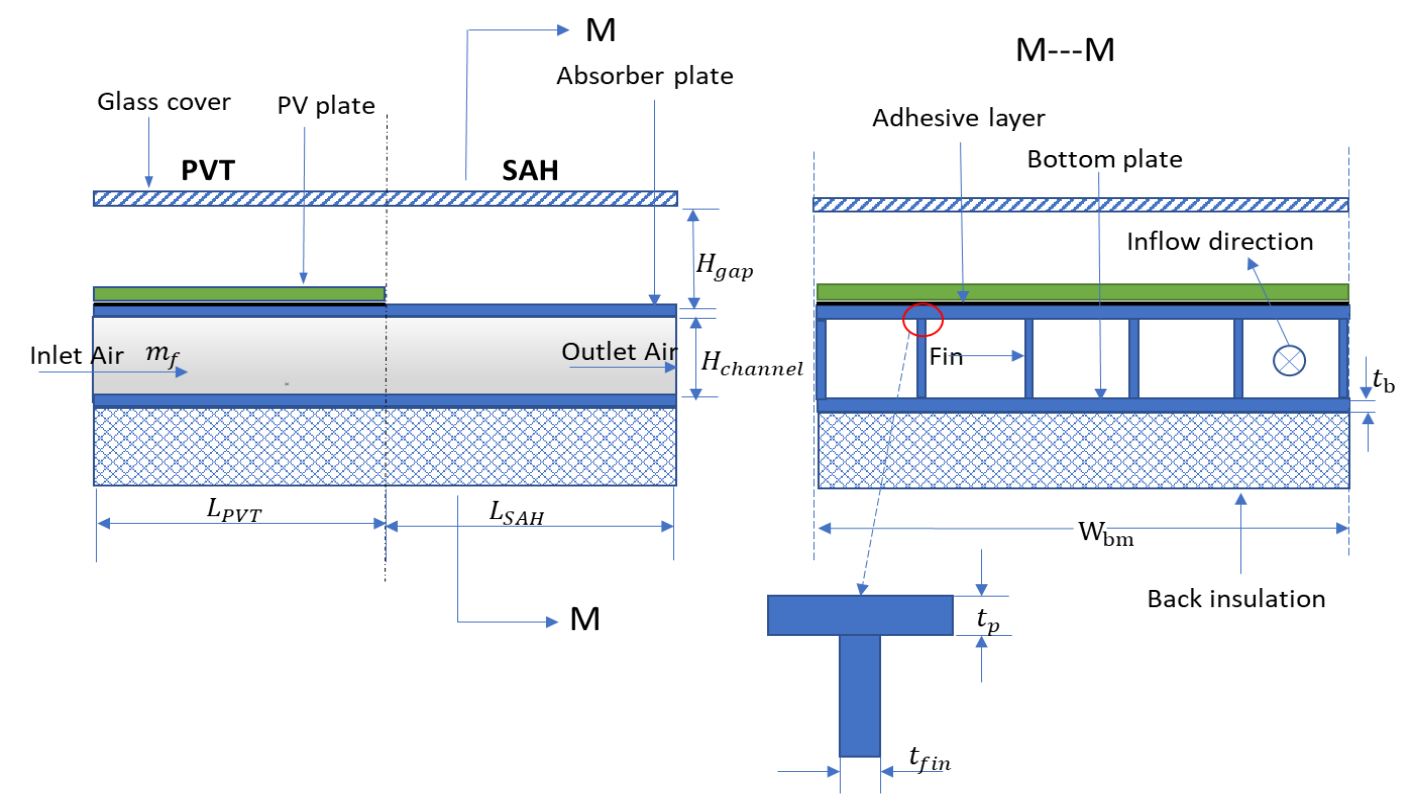

Figure 6. Section-view of the benchmark PVT-SAH system [28].

\section{$279 \quad 6.2$ Model validation results}

\section{$280 \quad 6.2 .1 \quad$ Validation methodology}

281 An experimental facility that is of the same design configuration with the heat pipe integrated PVT-SAH system

282 was not available in this study and the same system has not been previously reported in the literature. For this 283 reason, the PVT-SAH system that uses heat pipes was decomposed into two stand-alone parts as shown in Figure 2847 (a) and (b) for separate validation and the coupling between the two stand-alone parts was also verified with an analytical method. To validate the modelling of the components that comprise each part, the energy balance equations were modified to exclude the components describing heat exchanges with the other part. 

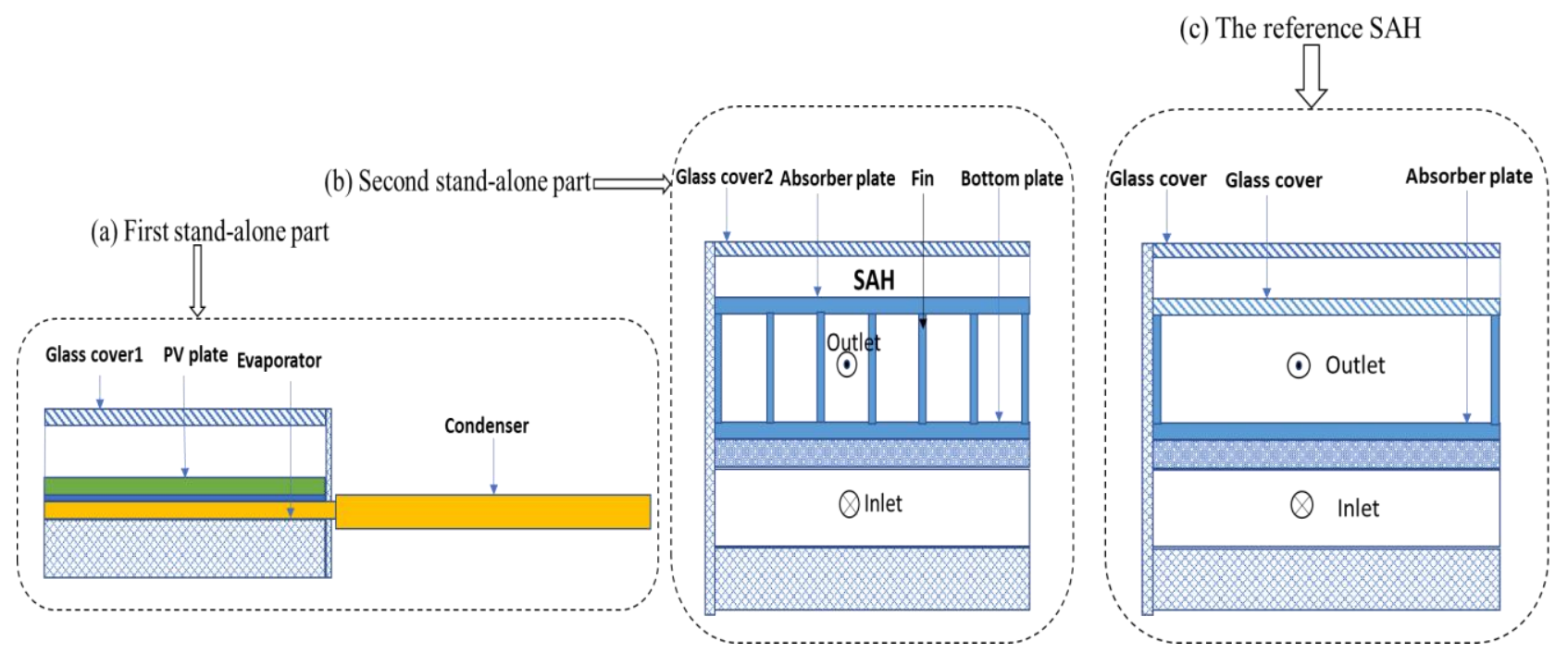

Figure 7. The schematics of (a)first stand-alone part, (b)second stand-alone part and (c) reference SAH in Ho, Yeh and Wang [48].

The validation process comprises three steps. In the first step, the first stand-alone part was validated with the experimental data of a heat-pipe type PVT that was published in the literature [20]. The time-varying conditions, the temperature of a condenser and the design parameters (Table 2) reported in [20] were used as the inputs of the first stand-alone part model. The transient temperatures of the various construction components predicted were then compared with the published experimental data.

Table 2. The values of the design parameters of the first stand-alone part used for model validation.

\begin{tabular}{ll}
\hline Design parameter & Value \\
\hline Length $(\mathrm{mm})$ & 962 \\
Width (mm) & 1,260 \\
Thickness of back plate (mm) & 1.16 \\
Number of heat pipes (mm) & 9 \\
Distance between adjacent heat pipes (mm) & 140 \\
Dimensions of the evaporator (mm) & $\varphi 8 \times 0.7 \times 1000$ \\
Dimensions of the condenser & $\varphi 24 \times 1 \times 120$ \\
Air gap thickness between glass cover and PV panel $(\mathrm{mm})$ & 40 \\
Thickness of the insulation behind the back plate $(\mathrm{mm})$ & 50 \\
Reference PV efficiency $(\%)$ & 15.5 \\
\hline
\end{tabular}

In the second step, the experimental data of a double pass SAH presented by Ho et al. [48] was employed to validate the model of the second stand-alone part. The double-pass SAH [48] (Figure 7(c)) had the same geometrical structure with the second stand-alone part in this paper with exception of the following: 1) the reference SAH had no longitudinal fins in the upper channel; 2) The upper channel of the reference system (Figure 7 (c)) was formed 
by a glass cover and an absorber plate while the upper channel second stand-alone part (Figure 7(b)) was composed of an absorber plate and a bottom plate.

To make the necessary modifications and account for these differences, the following actions were taken: 1) the number of fins (a design parameter of the model in this study) was set to zero and; 2) the optical and thermalphysical properties of the absorber plate and bottom plate of the second stand-alone part (solar transmissivity, absorptivity, and emissivity in Table 3) were set to be the same as those of the glass cover and absorber plate of the reference SAH in [48]. In addition, the model of the second standalone part was adjusted to take into account the impact of the recycle ratio as studied in the reference literature [48].

Table 3. Major design parameters used to validate the second separated part of the PVT-SAH system.

\begin{tabular}{llll}
\hline Parameter & Value & Parameter & Value \\
\hline Solar absorptivity of the absorber plate & 0.01 & Solar absorptivity of the bottom plate & 0.96 \\
Solar transmissivity of the absorber plate & 0.875 & Solar emissivity of the bottom plate & 0.8 \\
Solar emissivity of the absorber plate & 0.94 & & \\
\hline
\end{tabular}

In the third step, the coupling of the two stand-alone parts was confirmed with an analytical method by using constant boundary conditions (i.e. solar radiation $1000 \mathrm{~W} / \mathrm{m}^{2}$, ambient temperature $25^{\circ} \mathrm{C}$ and wind speed $3 \mathrm{~m} / \mathrm{s}$ ). Firstly, the temperatures of the construction components and the flowing air of the heat pipe integrated PVT-SAH system were calculated. Secondly, as the flowing air in the lower channel is the point where the two stand-alone parts are coupled, the obtained flowing air temperature in the lower channel from the coupled model as well as the constant weather conditions were assigned to the models of two stand-alone parts as the boundary conditions respectively. Finally, the temperature of the construction components obtained from the stand-alone parts were then compared with the results from the coupled model.

\subsubsection{Results from the model validation of the first stand-alone part}

Figure 8 compares the simulated temperatures of the PV plate, back sheet ("BS" in Figure 8) and the evaporator ("eva" in Figure 8) with the measured temperatures from Gang et al. [20]. The differences between the modelling 
321 relative root mean square deviation (NRMSD) as shown in Table 4. The values of RMSD for all construction

322 components were less than $1{ }^{\circ} \mathrm{C}$ and the NRMSD was below $2 \%$, which indicated a good match of the first stand-

323 alone part model with the reference data.
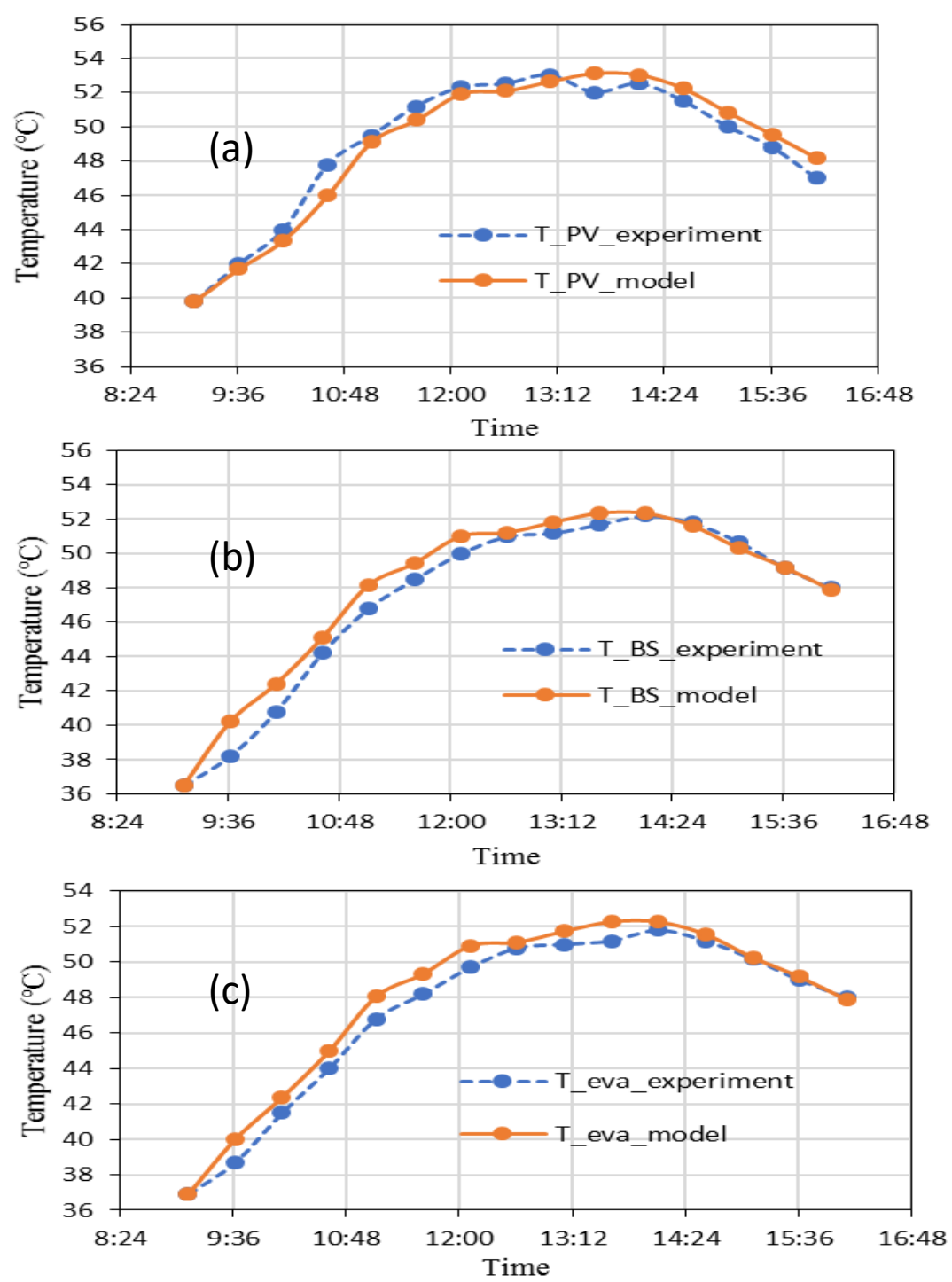

Figure 8. Comparisons of the temperature of (a) PV plate, (b) back-sheet and (c) evaporator between the experimental data from Gang et al. [20] and the simulation data.

Table 4. Relative differences between experimental and modelling results for the first stand-alone part of the PVT-SAH with heat pipes.

\begin{tabular}{llll}
\hline Indicators & PV plate & Back sheet plate & Evaporator \\
\hline RMSD & $0.81 \mathrm{C}^{\circ}$ & $0.90 \mathrm{C}^{\circ}$ & $0.82 \mathrm{C}^{\circ}$ \\
NRMSD & $1.65 \%$ & $1.91 \%$ & $1.72 \%$ \\
\hline
\end{tabular}


6.2.3 Results from the model validation of the second stand-alone part

Figure 9 shows the thermal efficiency predicted by the second stand-alone part model, which agreed well with the $\mathrm{kg} / \mathrm{hr}$.

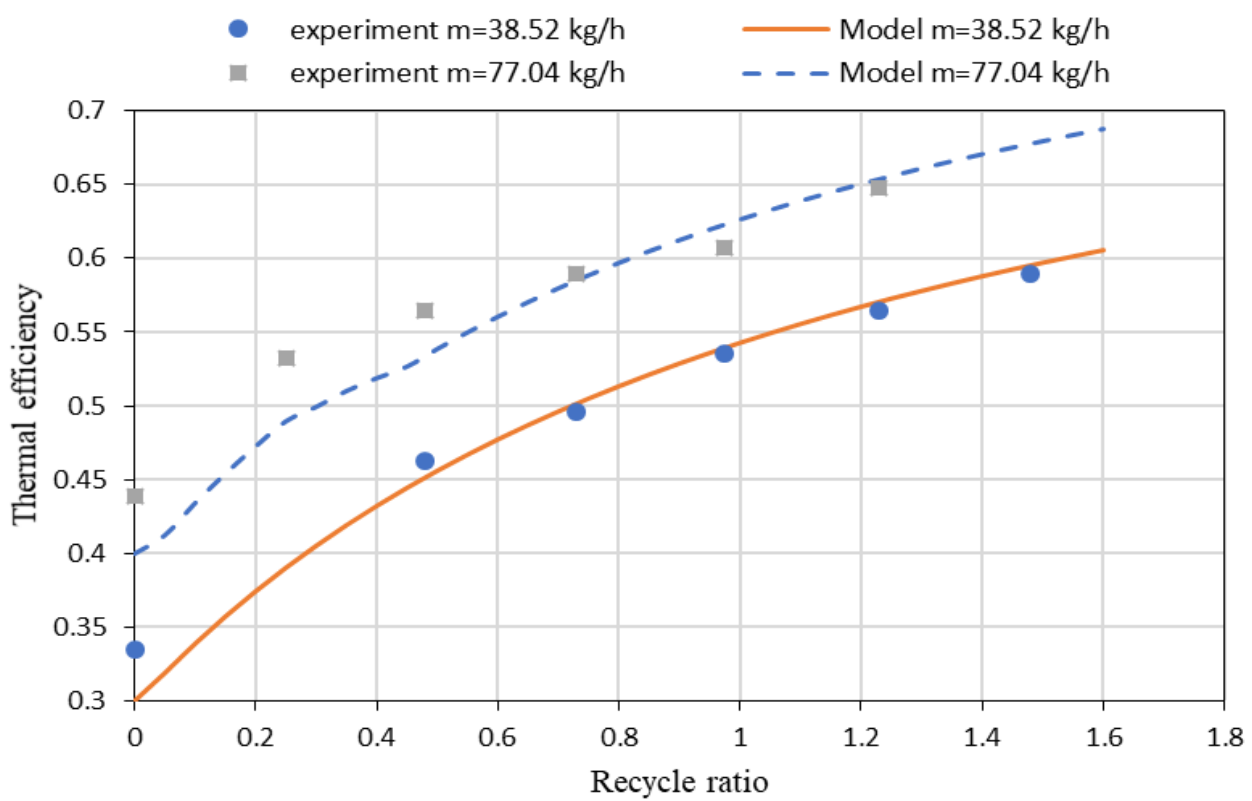

Figure 9. Measured and modelled thermal efficiency of the second stand-alone part (double pass solar air heater).

\subsubsection{Results from the analytical verification of the coupling between the two stand-alone parts}

337 In Figure $10(\mathrm{a})$, the temperatures of the construction components (PV plate $\left(T_{p v}\right)$, evaporator $\left(T_{\text {eve }}\right)$ and condenser $\left.\left(T_{c o}\right)\right)$ and the heat pipe working fluid $\left(T_{w f}\right)$ that were predicted by the first stand-alone part model matched exactly the temperature curves predicted by the coupled model. Similarly, the second stand-alone part model and the coupled model showed no difference in predicting the component temperatures (glass cover 2 (T_g2), flowing air in upper channel (T_f2) and lower channel (T_f1), absorber plate (T_p) and bottom plate $\left(T_{-} b\right)$ ) as seen in Figure 10 (b). These results demonstrated the correct coupling between the models of the two stand-alone parts. 

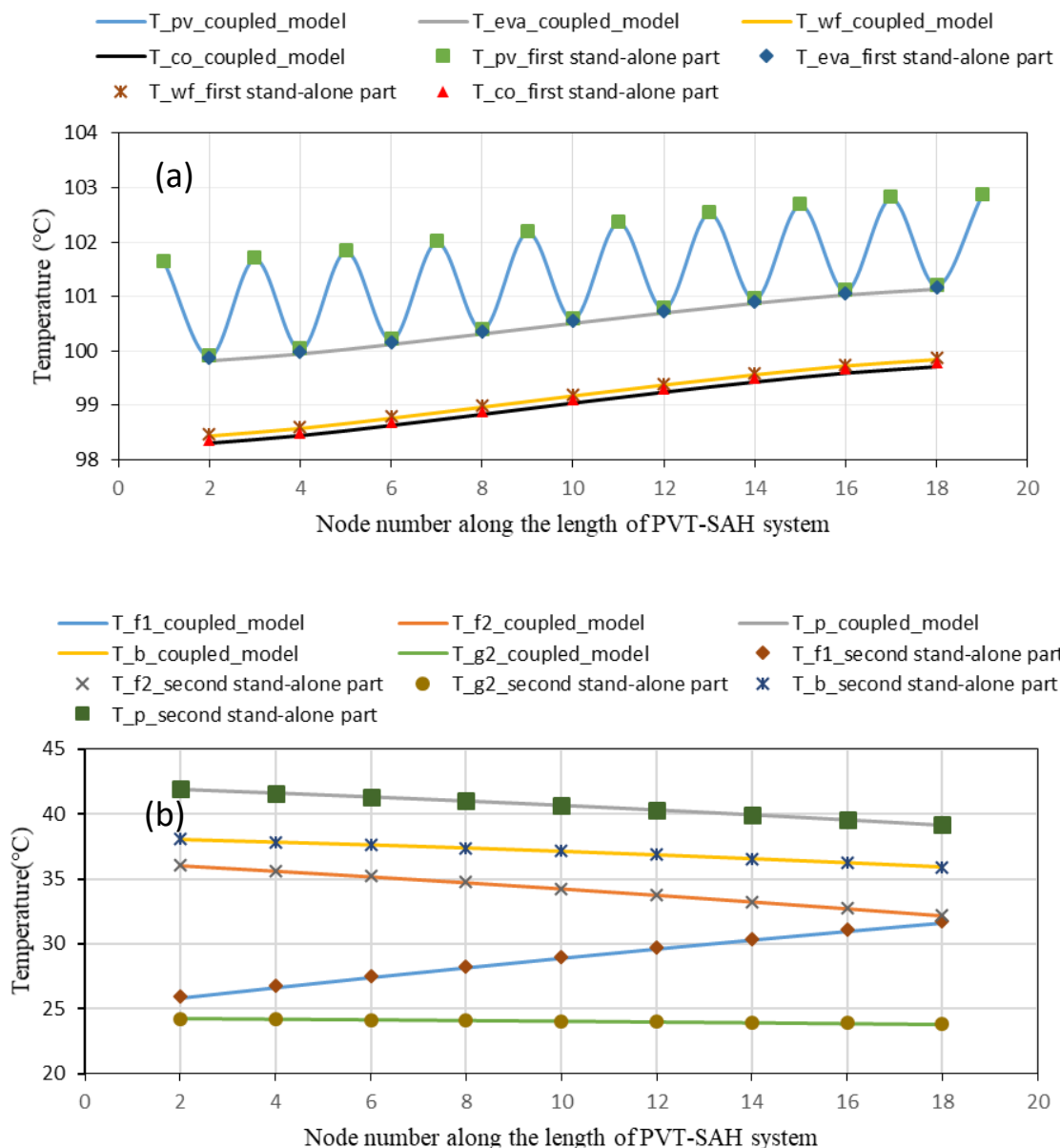

344 Figure 10. Comparisons of the predicted node temperatures (a) between the coupled heat pipe PVT-SAH model and the first stand-alone part model; (b) between the coupled heat pipe PVT-SAH model and the second stand-alone part model.

\subsection{Results from the energy performance analysis}

347 The optimal thermal performance and electrical performance are represented by the optimal Pareto Fronts obtained 348 from the multi-objective design optimisation of the heat pipe PVT-SAH and benchmark PVT-SAH for different system lengths, and are presented in Figure 11 (a) to (c). The capital costs calculated for each design are also shown in Figure 11. The optimal Pareto Fronts represented a hierarchy of the best possible trade-offs between the useful thermal efficiency and net electrical efficiency. It was found that, for the same electrical efficiency, the PVT-SAH systems with heat pipes achieved a higher useful thermal efficiency than the benchmark designs. The useful thermal efficiencies of the PVT-SAH system with heat pipes and the benchmark PVT-SAH are summarised in Table 5. 
Table 5. Useful thermal efficiency of Pareto Fronts of PVT-SAH systems considering different system lengths.

\begin{tabular}{llc}
\hline \multirow{2}{*}{ System Length } & \multicolumn{2}{c}{ Thermal efficiency } \\
\cline { 2 - 3 } & Benchmark design & PVT-SAH with heat pipes \\
\hline $4 \mathrm{~m}$ & $27.1-60.2 \%$ & $33.5-67.2 \%$ \\
$10 \mathrm{~m}$ & $31.0-61.7 \%$ & $33.2-67.5 \%$ \\
$16 \mathrm{~m}$ & $30.3-61.7 \%$ & $27.6-69.2 \%$ \\
\hline
\end{tabular}

Three candidate points (Option 1/Option 2/Option 3) which respectively represented the highest, equal weighting and lowest preference levels on the thermal energy, were marked in Figure 11 for each set of Pareto Fronts. The design specifications and performance of these chosen optimal candidate designs are summarised in Table 6. It was also noted that the useful thermal efficiency of a few candidate designs of the heat pipe PVT-SAH with large electrical efficiencies dropped below the benchmark designs (Figure 11). This is because the designs with a higher net electrical efficiency correspond to a larger value of the PV covering factor $\left(r_{p v}\right)$ which can be observed in Table 6. The increasing PV covering factor was reversely proportional to the width of the air channel of the PVT-SAH which in turn reduced the transfer areas between the flowing air and condenser side of the heat tubes.

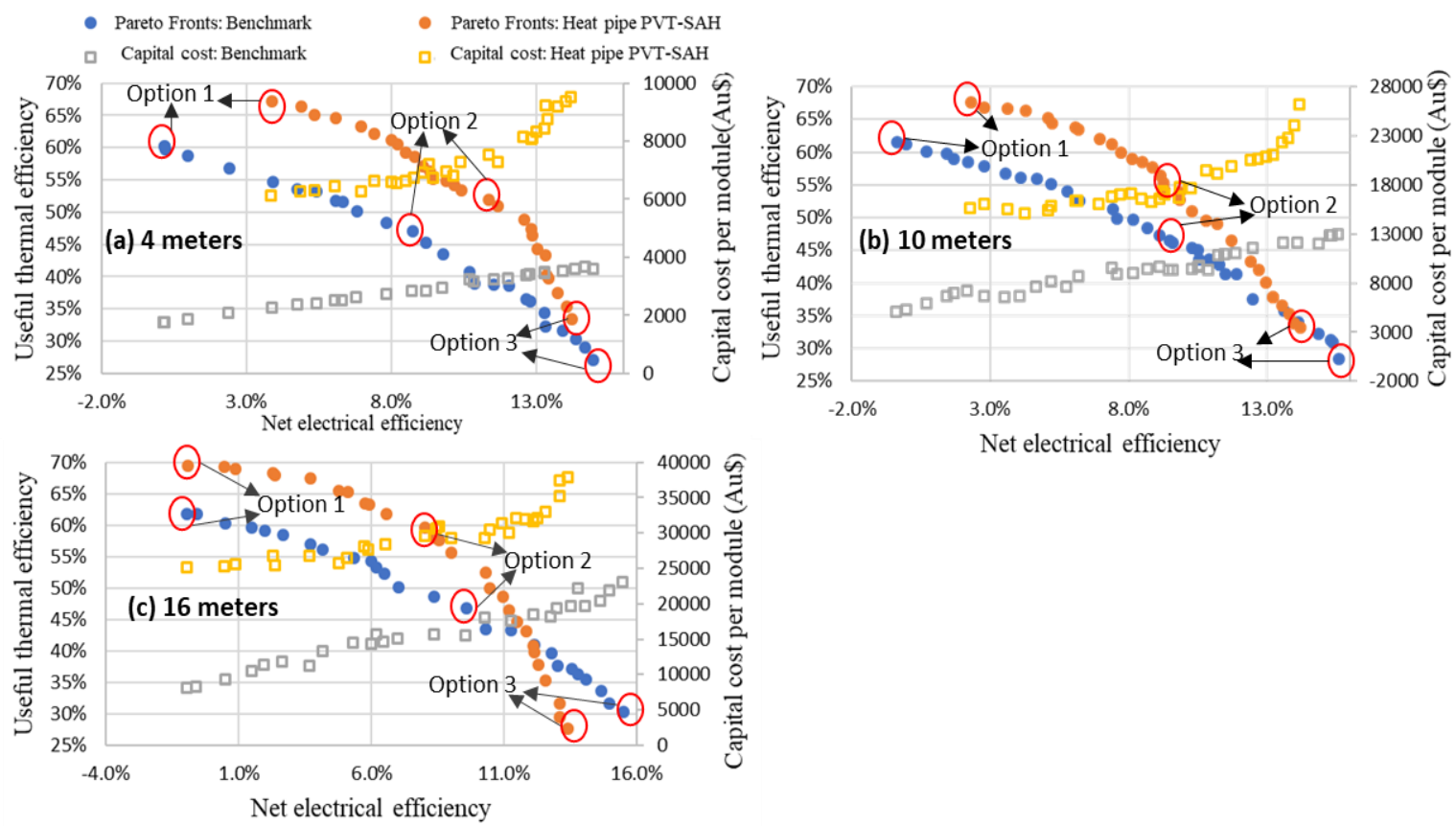

Figure 11. Pareto Fronts obtained from the optimization of the heat pipe type and benchmark PVT-SAH systems and corresponding capital costs for each system for different lengths i.e. (a) 4 meters, (b) 10 meters and (c) 16 meters. 
Table 6. Optimal design parameters and energy performance of the candidate designs of the benchmark and heat pipe integrated PVT-SAH systems.

\begin{tabular}{|c|c|c|c|c|c|c|c|c|c|c|c|c|c|c|}
\hline \multicolumn{15}{|c|}{ Benchmark PVT-SAH systems } \\
\hline \multirow{2}{*}{$\begin{array}{l}\text { Candid } \\
\text { ate No. }\end{array}$} & \multirow{2}{*}{$\begin{array}{l}\text { System } \\
\text { Length } \\
(\mathrm{m})\end{array}$} & \multirow{2}{*}{$\begin{array}{l}\text { Priority } \\
\text { on } \\
\text { thermal } \\
\text { energy } \\
\text { gains }\end{array}$} & \multicolumn{9}{|c|}{ Key design parameters } & \multicolumn{3}{|c|}{ Energy performance } \\
\hline & & & $\begin{array}{l}\text { Channel } \\
\text { depth } \\
H_{\text {channel }} \\
\text { (cm) }\end{array}$ & \multicolumn{2}{|c|}{$\begin{array}{l}\text { Number of } \\
\text { fins } \\
N_{\text {fin }} \\
(-)\end{array}$} & \multicolumn{2}{|c|}{$\begin{array}{l}\text { Thickness of } \\
\text { air gap } \\
H_{\text {gap }} \\
(\mathrm{cm})\end{array}$} & $\begin{array}{l}\text { PV } \\
\text { covering } \\
\text { factor } \\
r_{p v} \\
(-)\end{array}$ & \multicolumn{2}{|c|}{$\begin{array}{l}\text { Air mass flow } \\
\text { rate } \\
\dot{M}_{f} \\
(\mathrm{~kg} / \mathrm{hr})\end{array}$} & $\begin{array}{l}\text { PV reference } \\
\text { efficiency } \\
\eta_{r e f, p v} \\
(\%)\end{array}$ & $\begin{array}{l}\text { Useful } \\
\text { thermal } \\
\text { efficiency } \\
\eta_{t h} \\
(\%)\end{array}$ & $\begin{array}{l}\text { Net } \\
\text { electrical } \\
\text { efficiency } \\
\eta_{\text {ele }} \\
(\%)\end{array}$ & $\begin{array}{l}\text { Average } \\
\text { thermal } \\
\text { capacity } \\
E_{t h} \\
(\mathrm{~kW})\end{array}$ \\
\hline 1 & \multirow[t]{3}{*}{$4 \mathrm{~m}$} & Option 1 & 1.1 & 37 & \multicolumn{3}{|c|}{5.8} & 0 & 112 & \multicolumn{2}{|c|}{-} & 60.2 & 0 & 1.14 \\
\hline 2 & & Option 2 & 1.2 & 36 & \multicolumn{3}{|c|}{5.1} & 0.55 & 118 & \multicolumn{2}{|c|}{18} & 47.0 & 8.7 & 0.89 \\
\hline 3 & & Option 3 & 1.3 & 29 & \multicolumn{3}{|c|}{2.6} & 1 & 125 & \multicolumn{2}{|r|}{18} & 27.1 & 14.9 & 0.51 \\
\hline 4 & \multirow[t]{3}{*}{$10 \mathrm{~m}$} & Option 1 & 1.1 & 56 & \multicolumn{3}{|c|}{5.9} & 0 & 295 & \multicolumn{2}{|c|}{-} & 61.7 & -1.0 & 2.93 \\
\hline 5 & & Option 2 & 3.3 & 54 & \multicolumn{3}{|c|}{5.2} & 0.61 & 299 & \multicolumn{2}{|c|}{18} & 46.5 & 9.4 & 2.21 \\
\hline 6 & & Option 3 & 5.5 & 53 & \multicolumn{3}{|c|}{4.9} & 1 & 303 & \multicolumn{2}{|c|}{18} & 31.0 & 15.3 & 1.47 \\
\hline 7 & $16 \mathrm{~m}$ & Option 1 & 1.9 & 50 & \multicolumn{3}{|c|}{5.9} & 0 & 416 & . & - & 61.7 & -0.9 & 4.72 \\
\hline 8 & & Option 2 & 4.0 & 50 & & 5.6 & & 0.63 & 413 & & 18 & 46.8 & 9.6 & 3.55 \\
\hline 9 & & Option 3 & 7.9 & 52 & & 2.0 & & 1 & 437 & & 18 & 30.3 & 15.4 & 2.30 \\
\hline & & & & & & Hea & oipe inte & ted PVT-S & H systems & & & & & \\
\hline Candid & System & Priority & Key desig & parameter & & & & & & & & Energy pe & ormance & \\
\hline ate No. & $\begin{array}{l}\text { Length } \\
(\mathrm{m})\end{array}$ & $\begin{array}{l}\text { on } \\
\text { thermal } \\
\text { energy } \\
\text { gains }\end{array}$ & $\begin{array}{l}\text { Height of } \\
\text { upper } \\
\text { channel } \\
H_{\text {channel2 }} \\
(\mathrm{cm})\end{array}$ & $\begin{array}{l}\text { Height of } \\
\text { lower } \\
\text { channel } \\
H_{\text {channel1 }} \\
(\mathrm{cm})\end{array}$ & $\begin{array}{l}\mathrm{Nu} \\
\text { of } \mathrm{f} \\
N_{f i} \\
(-)\end{array}$ & & $\begin{array}{l}\text { Number } \\
\text { of heat } \\
\text { pipes } \\
N_{h p} \\
(-)\end{array}$ & $\begin{array}{l}\text { Thickness } \\
\text { of } \\
\text { connection } \\
\text { layer } \\
H_{\text {insu }} \\
(\mathrm{cm})\end{array}$ & $\begin{array}{l}\mathrm{PV} \\
\text { covering } \\
\text { factor } \\
r_{p v} \\
(-)\end{array}$ & $\begin{array}{l}\text { Air } \\
\text { mass } \\
\text { flow } \\
\text { rate } \\
\dot{M}_{f} \\
(\mathrm{~kg} / \mathrm{hr} \\
)\end{array}$ & $\begin{array}{l}\text { Diameter } \\
\text { of heat } \\
\text { pipes } \\
D_{h p} \\
(\mathrm{~cm})\end{array}$ & $\begin{array}{l}\text { Useful } \\
\text { thermal } \\
\text { efficiency } \\
\eta_{t h} \\
(\%)\end{array}$ & $\begin{array}{l}\text { Net } \\
\text { electrical } \\
\text { efficiency } \\
\eta_{\text {ele }} \\
(\%)\end{array}$ & $\begin{array}{l}\text { Average } \\
\text { thermal } \\
\text { capacity } \\
E_{t h} \\
(\mathrm{~kW})\end{array}$ \\
\hline 10 & $4 \mathrm{~m}$ & Option 1 & 2.3 & 4.1 & 28 & & 55 & 15 & 0.20 & 135 & 2.5 & 3.5 & 67.2 & 1.27 \\
\hline 11 & & Option 2 & 5.3 & 5.6 & 26 & & 54 & 15 & 0.72 & 133 & 3.3 & 51.8 & 11.3 & 0.98 \\
\hline 12 & & Option 3 & 9.8 & 11.8 & 17 & & 54 & 15 & 0.90 & 109 & 4.9 & 33.5 & 14.2 & 0.63 \\
\hline 13 & $10 \mathrm{~m}$ & Option 1 & 2.1 & 5.6 & 33 & & 91 & 15 & 0.20 & 300 & 3.9 & 67.5 & 2.3 & 3.20 \\
\hline 14 & & Option 2 & 4.8 & 8.9 & 18 & & 97 & 15 & 0.53 & 271 & 4.1 & 57.6 & 8.8 & 2.73 \\
\hline 15 & & Option 3 & 9.9 & 12.7 & 10 & & 110 & 15 & 0.90 & 220 & 5.9 & 33.2 & 14.2 & 1.57 \\
\hline 16 & $16 \mathrm{~m}$ & Option 1 & 1.7 & 7.8 & 35 & & 137 & 15 & 0.20 & 523 & 4.3 & 69.4 & -0.9 & 5.27 \\
\hline 17 & & Option 2 & 7.6 & 11.4 & 31 & & 134 & 15 & 0.48 & 363 & 5.4 & 59.5 & 8.0 & 4.52 \\
\hline 18 & & Option 3 & 9.6 & 15.5 & 17 & & 131 & 15 & 0.90 & 152 & 7.9 & 27.6 & 13.4 & 2.09 \\
\hline
\end{tabular}




\subsection{Temperature distribution of the PV panels}

371 A separate case study was performed to investigate the temperature distribution across the PV panels and the 372 cooling effect from the use of the heat pipes in the proposed double pass PVT-SAH system. The specifications of some key parameters of the heat pipe PVT-SAH and the benchmark design are listed in Table 7. The typical-day weather conditions of September (which has the highest solar radiation and ambient temperature amongst all months), as shown in Figure 5, were employed as an example to perform the daytime simulation.

Table 7. Design specifications of some key parameters of the heat pipe PVT-SAH and benchmark design

\begin{tabular}{llll}
\hline Heat pipe integrated PVT-SAH & & Benchmark PVT-SAH & \\
Design parameter & Value & Design Parameters & Value \\
\hline Length of PVT-SAH & $4 \mathrm{~m}$ & Length of PVT-SAH & $4 \mathrm{~m}$ \\
Length of PV & $4 \mathrm{~m}$ & Length of PV $\left(L_{P V T}\right)$ & $4 \mathrm{~m}$ \\
Width of PV $\left(W_{P V}\right)$ & $1 \mathrm{~m}$ & Width of PV & $1 \mathrm{~m}$ \\
Height of lower air channel $\left(H_{\text {channel } 1}\right)$ & $0.08 \mathrm{~m}$ & Air Channel depth $\left(H_{\text {channel }}\right)$ & $0.08 \mathrm{~m}$ \\
Width of the lower Air channel $\left(W_{S A H}\right)$ & $1 \mathrm{~m}$ & Air channel width $\left(W_{b m}\right)$ & $1 \mathrm{~m}$ \\
Number of heat pipes $\left(N_{h p}\right)$ & 70 & Number of fins $\left(N_{f i n}\right)$ & 50 \\
Length of heat pipes & $2 \mathrm{~m}$ & & \\
Diameter of the heat pipes $\left(D_{h p}\right)$ & $0.03 \mathrm{~m}$ & & \\
\hline
\end{tabular}

377 From Figure 12 (a) and (c), the temperatures of the PV panel for both systems increased as expected along the air flow direction, however a smaller temperature variation along the length (air flow direction) of the PV panel was observed for the PVT-SAH system with heat pipes. The maximum temperature variation was $9.4{ }^{\circ} \mathrm{C}$ for the PVTSAH system with heat pipes when the incident solar radiation was at its peak while the same variation for the benchmark design was $21^{\circ} \mathrm{C}$. The improved temperature homogeneity of the PV panel indicated that the heat pipes can deliver more efficient temperature control and cooling effects to the PV panels. The higher heat transfer efficiency of the heat pipes also led to a higher increase of the temperature of the outlet air from the lower channel of the heat pipe PVT-SAH (Figure 12 (b)) than the benchmark design (Figure 12 (d)). The selection of an appropriate type of working fluid, the liquid filling ratio of the heat pipes as well as the pitch distance have the undertaken in this study. 
(a): PV panel of heat pipe PVT-SAH

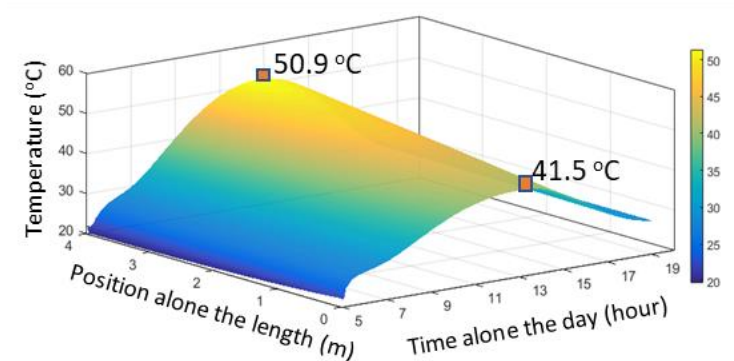

(c): PV panel of benchmark design

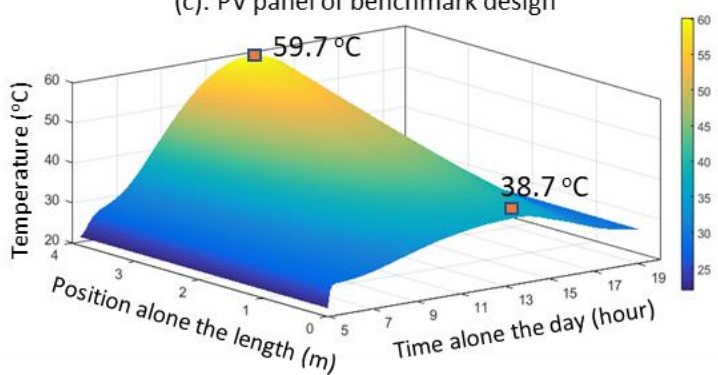

(b): flowing air in the lower channel of heat pipe PVT-SAH

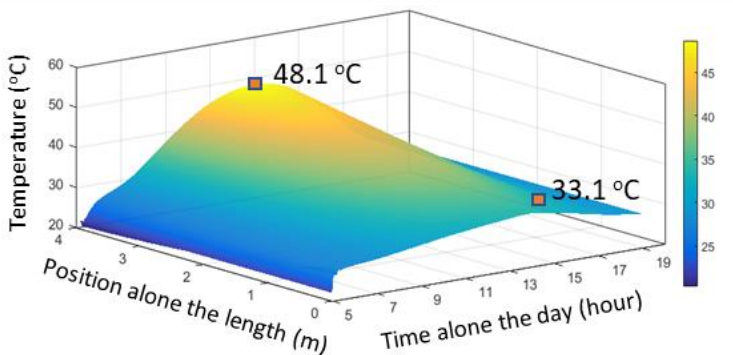

(d): flowing air of benchmark design

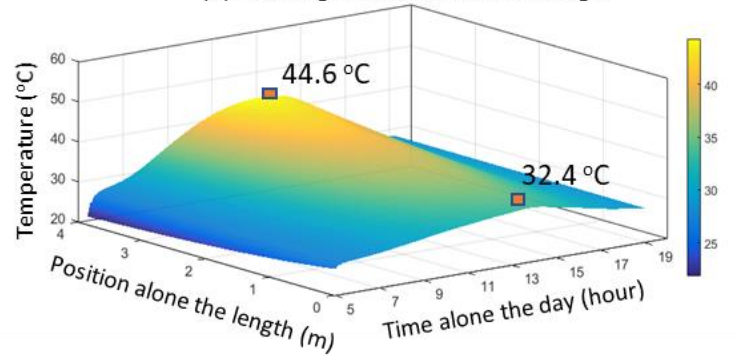

Figure 12. Temperature distribution of the PV panel and flowing air along the system length over time.

\subsection{Results from the economic analysis}

The 18 candidate designs considered were sized to meet a thermal demand of $5.5 \mathrm{~kW}$ and their economic performance was evaluated based on the three predefined economic indicators that were described in Section 5. It is worth to note that the ALCS is linearly dependent on the size of the PVT-SAH systems while the other two indicators (PBT and CCKT) are independent of the system size.

The CCKT of the heat pipe PVT-SAH systems and the benchmark designs are presented in Figure 13 (a). The candidate designs were grouped according to the type and length of the system. In each group, Option 3 showed the highest value of CCKT which was then followed by Option 2 and Option 1 . This can be explained by the fact that the designs of Option 3 (with the highest preference on electricity gains) were optimised with larger values of the PV covering factor, channel depth and diameter of heat pipes, which in turn increased the areas of the PV panel and other construction materials, hence increasing the capital cost. The benchmark designs performed better in terms of CCKT than the heat pipe designs and Option 1 of the benchmark PVT-SAH system (i.e. the option that includes only a SAH) showed the lowest capital cost. 
As seen from Figure 13 (b), the benchmark designs showed a higher value of ALCS than the heat pipe PVT-SAH systems, and its minimum value of ALCS $(A \$ 4,864)$ was higher than the maximum value of ALCS of the heat pipe PVT-SAH systems $(A \$ 4,606)$. For heat pipe PVT-SAH systems, a dramatical drop of ALCS can be observed for Option 3 (high PV covering factor), especially for the system with the longest length. This is due to the significant increase in the capital cost (see Figure 11) introduced by the larger PV areas and the other components. Contrary to the heat pipe PVT-SAH, the candidate benchmark designs with a higher PV covering factor (Option 2 and Option 3) performed better than the designs with a lower PV covering factor (Option 1) with respect to the ALCS. The reason is that the increased fuel saving due to the electricity production from the PV panel was larger than the capital cost used for the installation of PV panels and other components.

Figure 13 (c) shows the payback time of all the candidate designs considered in this study. It can be seen that the results followed the same trend as the CCKT results. The PBT of any design was shorter than the life cycle (20 years), particularly for Option 1 of the benchmark design with the system length of $4 \mathrm{~m}$ which had a PBT of 1.8 years. The maximum PBT was 16.8 years for Option 3 of the heat pipe integrated PVT-SAH with the system length of $16 \mathrm{~m}$. The results showed that investment on any of those 18 designs can be paid back within an expected 20

417 years operation life of the system. In addition, the benchmark designs had approximately $50 \%$ shorter payback time than the heat pipe PVT-SAH systems regardless of the system characteristics. 

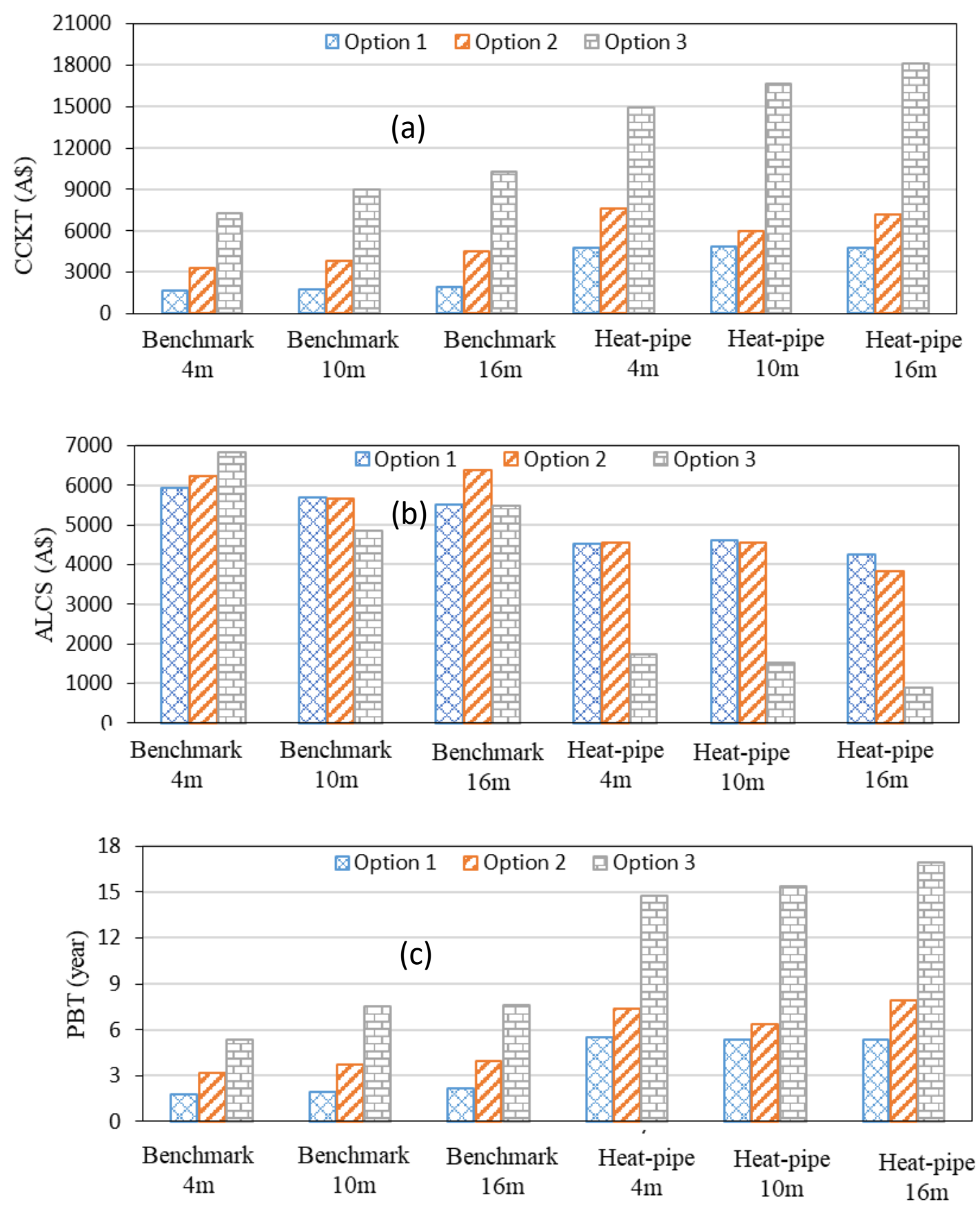

Figure 13. Economic performance of the 18 candidate designs of PVT-SAH systems (see Figure 11 for the 18 selected designs) with respect to (a) CCKT, (b) ALCS and (c) PBT.

\section{$422 \quad 6.6$ Sensitivity analysis of the economic performance}

423 The sensitivity of the three economic indicators to the variation of an individual construction or operation cost

424 parameter was evaluated by using the Monte Carlo simulation method. The variations of $\pm 40 \%$ and $\pm 50 \%$ were

425 applied to the baseline values of the construction and operation cost parameters as listed in Table 1. The design of 
426 Option 2 of $4 \mathrm{~m}$ long benchmark PVT-SAH was used for the sensitivity analysis and the results are presented in

$427 \quad$ Figure 14 and Figure 15.

428 From Figure 14 (a)-(b) it can be seen that the three economic performance indicators showed a linear relationship

429 with the changes in the construction cost parameters. The fabrication \& installation cost was the most influential

430 parameters to all the three performance indicators which was then followed by the steel price, thickness of steel

431 sheet and PV price, while the least influential factor was the cost of the selective coating film. CCKT and PBT

432 variations were more sensitive to the assumptions for the construction cost parameters than the ALCS.

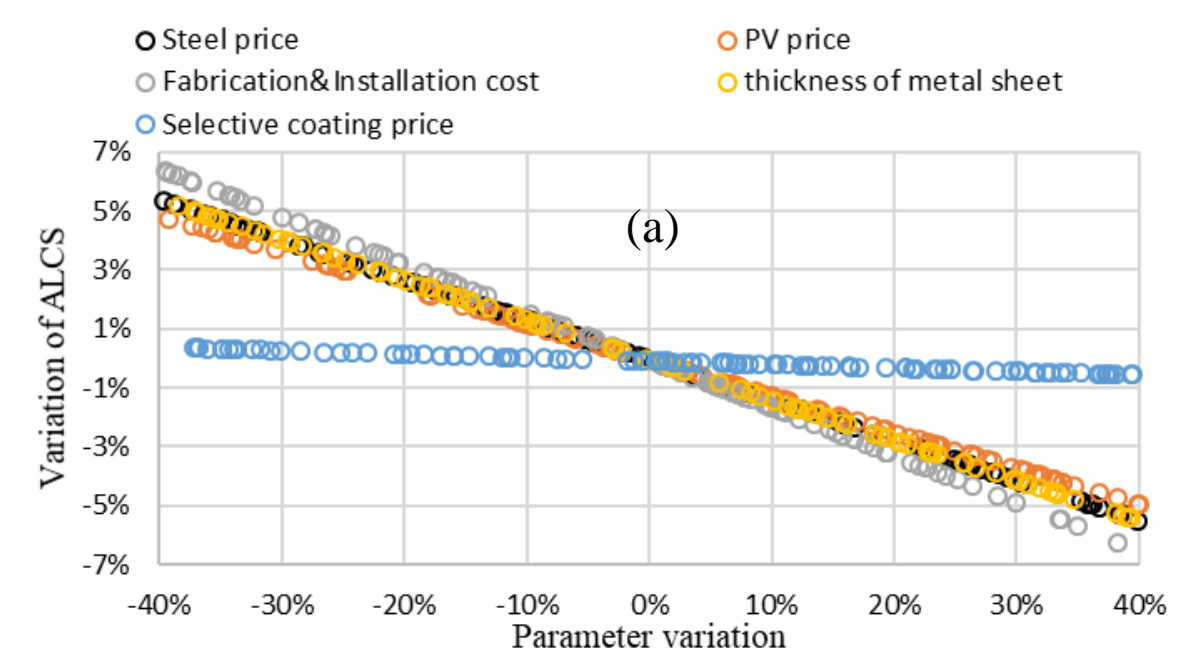

434 Figure 14. Influence of various construction cost parameters on the economic performance of the system (a) ALCD and, (b) CCKT and 
436 The operation cost parameters influenced the incomes and expense of running the PVT-SAH systems in the 437 operation stage. The electricity price per unit $\mathrm{kWh}$ and yearly escalation rate in electricity price determined how 438 much fuel saving (incomes) can be achieved. The interest rate and inflation rate influenced the amount of the cost 439 paid for the bank loan and the system maintenance respectively. Regarding ALCS, the most significant operation 440 cost parameters were electricity price per unit $\mathrm{kWh}$ and the escalation rate in the electricity price. The resultant 441 sensitivity for these two parameters was $\pm 68 \%$ and $\pm 10 \%$, respectively, as seen in Figure 15 (a). This means that 442 in the places where the electricity is more expensive, the application of PVT-SAH systems would be more 443 economically feasible. On the contrary, the increase of interest rate had negative effects on the ALCS with a sensitivity of $\pm 10 \%$. The effect of inflation rate on the ALCS was negligible, because only maintenance cost was subject to the yearly inflation rate and the relevant cost was at a lower magnitude in comparison with the fuel 446 savings and the other expenses. The electricity price was observed to be the most significant parameter for PBT.

447 For lower electricity prices, the rate of increase in the PBT increased in a non-linear way as shown in Figure 15 (b). 

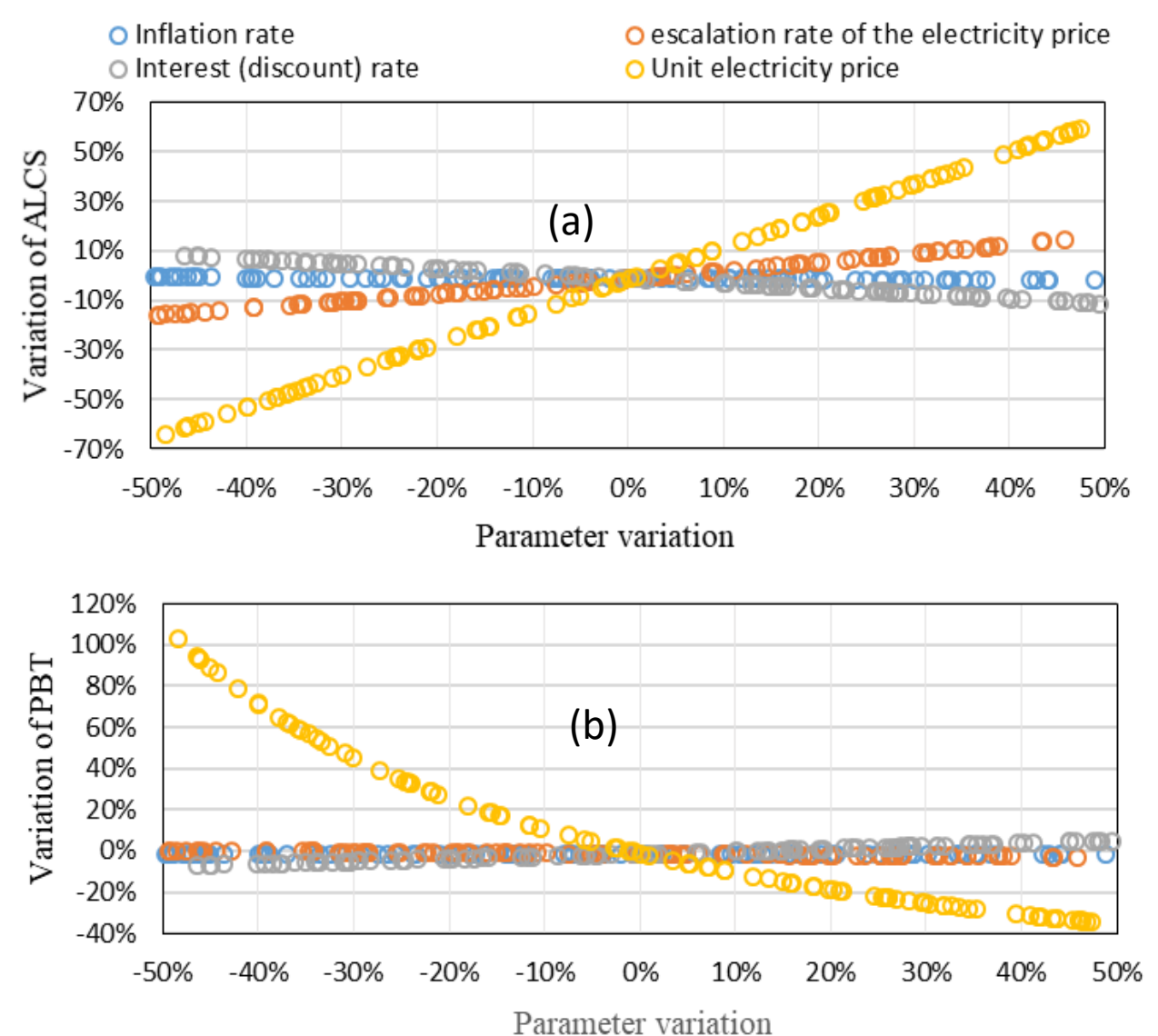

449 Figure 15. Influence of operation cost parameters (inflation rate, escalation rate of the electricity price, interest rate and electricity price for every kWh on the economic performance (a) ALCD and, (b) PBT.

\subsection{Uncertainty in the economic performance due to the combined effect of multiple parameters}

452 The construction and operation cost parameters affect the economic performance of the PVT-SAH systems at

453 different stages of the life cycle and for this reason, the overall uncertainties in the economic performance due to

454 these two grouped parameters were analysed separately. For each candidate design, the Monte Carlo method [49]

455 was employed to generate all possible combinations of either construction cost parameters or operation cost 456 parameters with a sampling size of 500. The overall uncertainties in the ALCS, PBT and CCKT due to the combined 457 impacts of construction cost parameters are respectively presented in Figure 16 (a), (b) and (c) for different candidate designs that are indexed from 1 to 18 . The index numbers were in accordance with the candidate number

459 listed in Table 6. The length of the error bar represented the range of uncertainties. 
The range of overall uncertainties in the economic performances varied significantly across different candidate 461 designs. For both heat pipe and benchmark PVT-SAH systems, the range of uncertainty in any of the performance indicators increased with greater PV covering factors (from Option 1 to Option 3). Overall, the PVT-SAH of

463 benchmark designs (design 1 to 9 in Figure 16) showed a relatively smaller range of uncertainty compared to heat 464 pipe PVT-SAH systems (design 10 to 18 in Figure 16). This means that the risks associated with investing on 465 benchmark designs can be lower when the prices of component materials change significantly. The three lowest ranges of uncertainties with respect to the ALCS were found for Option 1 of benchmark PVT-SAH systems (which are pure SAHs) with an uncertainty ranging from $\mathrm{A} \$ 703$ to $\$ A 491$ for the system length of 4 meters, $A \$ 626$ to $\mathrm{A} \$ 490$ for system length of 10 meters and $\mathrm{A} \$ 772$ to $\mathrm{A} \$ 592$ for system length of 16 meters, respectively. The design of Option 3 of the heat pipe PVT-SAH systems was the most volatile with regard of ALCS, with the lower bound 470 of the uncertainties to be $\mathrm{A} \$ 3140, \mathrm{~A} \$ 3855$ and $\mathrm{A} \$ 5212$ respectively for the system length of 4,10 and 16 meters.

471 The negative values of ALCS meant the investments on the PVT-SAH systems in the Option 3 of heat pipe PVT-

472 SAH cannot be paid back within the life cycle period (20 years) and this is also shown in Figure 16 (b). Similar conclusions as those for the impact of uncertainties on ALCS were also drawn for the PBT and CCKT. 

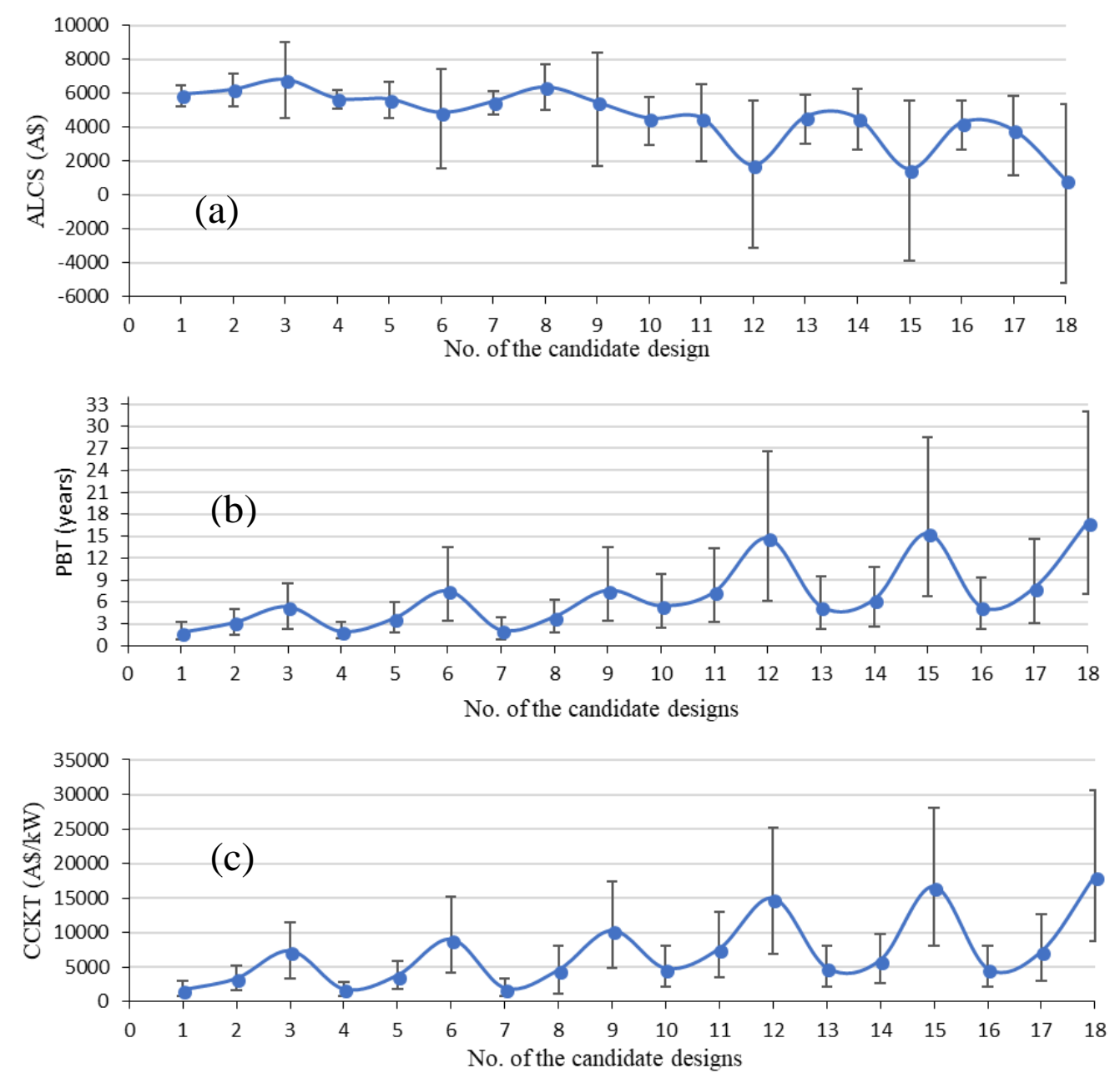

Figure 16. Overall uncertainties in the (a) ALCS, (b) PBT, (c) CCKT due to the combined effects of construction cost parameters.

477 The combined impacts of operation cost parameters that were included in Table 1 on the ALCS and PBT are shown

478 in Figure 17. It can be observed from Figure 17 (a) that the ranges of the uncertainties caused by operation cost 479 parameters were significantly larger than those by the construction cost parameters for all candidate designs considered. The values of ALCS of candidate designs 3, 6, 9, 11, 12, 14, 1517 and 18 were below zero, and therefore the time needed to pay off the investments on these designs was longer than the period of the life cycle of the system. To reduce the economic risks due to the uncertainties and increase the possibility for profits, the candidate designs with the no. of $1,2,4,5,7,8,10,13$ and 16 (see Table 6 ) were recommended The above results indicated that a low electricity price and high-interest rates could significantly reduce the economic feasibility of applying the PVT-SAH systems for the regeneration process of a desiccant wheel. 

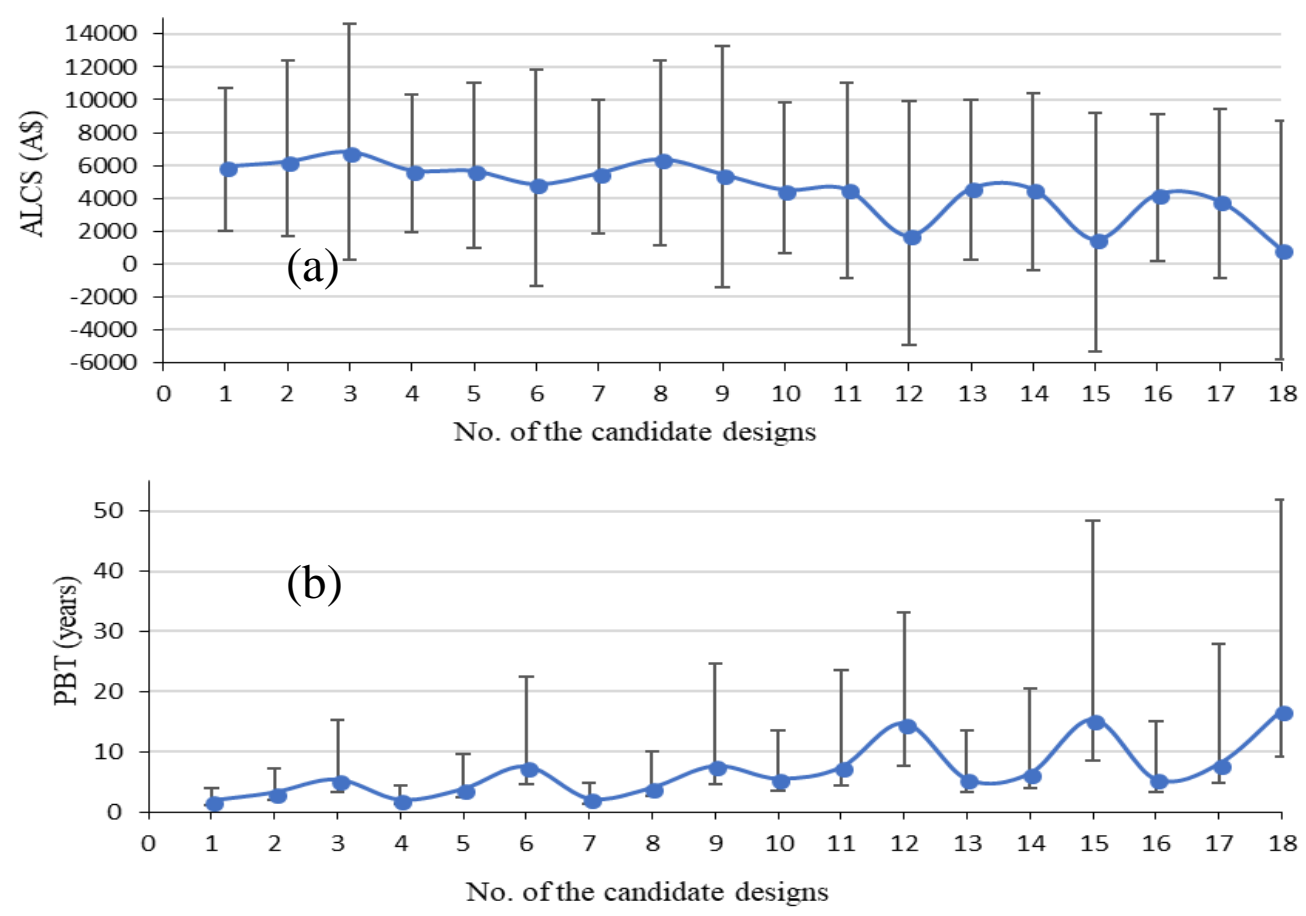

486

487

Figure 17. Overall uncertainties in the (a) ALCS, (b) PBT due to the combined effects of operation cost parameters.

\section{Conclusions}

A design of double pass heat pipe integrated PVT-SAH system was first developed which has the potential to drive a desiccant cooling system in summer. The developed energy performance model of the heat pipe integrated PVTSAH system was validated by comparing the simulation results with the reference data and good agreements were observed. The investigations of energy performance showed that the application of heat pipes bring stronger cooling effects to the PV panel and has the potential to achieve a higher level of uniformity in terms of the temperature distribution of the PV panel (the maximum temperature variation was $9.4{ }^{\circ} \mathrm{C}$ ) and therefore better temperature control in comparison with a benchmark PVT-SAH design (maximum temperature variation of $21.0^{\circ} \mathrm{C}$ ). Regardless of the system length, the optimal designs of the heat pipe PVT-SAH systems performed better than the benchmark PVT-SAH with respect to the useful thermal efficiency (maximum useful thermal efficiency was in the range of $67.2-69.2 \%$ for the heat-pipe PVT-SAHs and $60.2-61.7 \%$ for the benchmark designs) under the constraints of the same net electricity outputs. However, a better energy performance of the PVT-SAH with the heat pipes was 


\section{Acknowledgements}

\section{Declarations of interest: none.}




\section{References}

[1] C. Choudhury, P. Chauhan, H. Garg, Design curves for conventional solar air heaters, Renewable energy, 6 (7) (1995) 739-749.

[2] T.T. Chow, G. Pei, K. Fong, Z. Lin, A. Chan, J. Ji, Energy and exergy analysis of photovoltaic-thermal collector with and without glass cover, Applied Energy, 86 (3) (2009) 310-316.

[3] A.A. Hegazy, Performance of flat plate solar air heaters with optimum channel geometry for constant/variable flow operation, Energy Conversion and Management, 41 (4) (2000) 401-417.

[4] A. Omojaro, L. Aldabbagh, Experimental performance of single and double pass solar air heater with fins and steel wire mesh as absorber, Applied energy, 87 (12) (2010) 3759-3765.

[5] A. El-Sebaii, S. Aboul-Enein, M. Ramadan, E. El-Bialy, Year round performance of double pass solar air heater with packed bed, Energy Conversion and management, 48 (3) (2007) 990-1003.

[6] A. El-Sebaii, H. Al-Snani, Effect of selective coating on thermal performance of flat plate solar air heaters, Energy, 35 (4) (2010) 1820-1828.

[7] C. Kennedy, H. Price, Progress in development of high-temperature solar-selective coating, in: ASME 2005 International Solar Energy Conference, American Society of Mechanical Engineers, 2005, pp. 749-755.

[8] B. Prasad, J. Saini, Effect of artificial roughness on heat transfer and friction factor in a solar air heater, Solar energy, 41 (6) (1988) 555-560.

[9] A.-M.E. Momin, J. Saini, S. Solanki, Heat transfer and friction in solar air heater duct with V-shaped rib roughness on absorber plate, International journal of heat and mass transfer, 45 (16) (2002) 3383-3396.

[10] D. Gupta, S. Solanki, J. Saini, Thermohydraulic performance of solar air heaters with roughened absorber plates, Solar Energy, 61 (1) (1997) 33-42.

[11] H.-M. Yeh, C.-D. Ho, J.-Z. Hou, Collector efficiency of double-flow solar air heaters with fins attached, Energy, 27 (8) (2002) 715-727.

[12] K. Matrawy, Theoretical analysis for an air heater with a box-type absorber, Solar energy, 63 (3) (1998) $191-198$.

[13] J. Tonui, Y. Tripanagnostopoulos, Improved PV/T solar collectors with heat extraction by forced or natural air circulation, Renewable energy, 32 (4) (2007) 623-637.

[14] M.Y.H. Othman, B. Yatim, K. Sopian, M.N.A. Bakar, Performance analysis of a double-pass photovoltaic/thermal (PV/T) solar collector with CPC and fins, Renewable energy, 30 (13) (2005).

[15] E. Franklin, J. Coventry, Effects of highly non-uniform illumination distribution on electrical performance of solar cells, in: ANZSES Solar Conference, Newcastle, Australia, 2002.

[16] J.S. Coventry, Performance of a concentrating photovoltaic/thermal solar collector, Solar Energy, 78 (2) (2005) $211-222$. [17] M. Hu, R. Zheng, G. Pei, Y. Wang, J. Li, J. Ji, Experimental study of the effect of inclination angle on the thermal performance of heat pipe photovoltaic/thermal (PV/T) systems with wickless heat pipe and wire-meshed heat pipe, Applied Thermal Engineering, 106 (2016) 651-660.

[18] M.H. Elnaggar, Numerical investigation of characteristics of wick structure and working fluid of U-shape heat pipe for CPU cooling, Microelectronics Reliability, 54 (1) (2014) 297-302.

[19] K. Shukla, Heat pipe for aerospace applications - an overview, Journal of Electronics Cooling and Thermal Control, 5 (01) (2015) 1 .

[20] P. Gang, F. Huide, Z. Tao, J. Jie, A numerical and experimental study on a heat pipe PV/T system, Solar energy, 85 (5) (2011) 911-921.

[21] S.-Y. Wu, Q.-L. Zhang, L. Xiao, F.-H. Guo, A heat pipe photovoltaic/thermal (PV/T) hybrid system and its performance evaluation, Energy and buildings, 43 (12) (2011) 3558-3567.

[22] H. Ren, Z. Ma, W. Lin, W. Fan, W. Li, Integrating photovoltaic thermal collectors and thermal energy storage systems 
using phase change materials with rotary desiccant cooling systems, Sustainable Cities and Society, 36 (2018) $131-143$.

[23] W. Fan, G. Kokogiannakis, Z. Ma, Design optimisation of a double pass PV/T-solar air heater integrated with heat pipes, in: 4th International Conference on Building Energy and Environment, COBEE2018, Melbourne Australia, Melbourne, 2018, pp. 834-839.

[24] T.T. Chow, A review on photovoltaic/thermal hybrid solar technology, Applied Energy, 87 (2) (2010) $365-379$.

[25] B. Agrawal, G.N. Tiwari, Life cycle cost assessment of building integrated photovoltaic thermal (BIPVT) systems, Energy and Buildings, 42 (9) (2010) 1472-1481.

[26] V. Raman, G. Tiwari, Life cycle cost analysis of HPVT air collector under different Indian climatic conditions, Energy Policy, 36 (2) (2008) 603-611.

[27] S. Kumar, G.N. Tiwari, Life cycle cost analysis of single slope hybrid (PV/T) active solar still, Applied Energy, 86 (10) (2009) 1995-2004.

[28] W. Fan, G. Kokogiannakis, Z. Ma, A multi-objective design optimisation strategy for hybrid photovoltaic thermal collector (PVT)-solar air heater (SAH) systems with fins, Solar Energy, 163 (2018a) 315-328.

[29] W. Fan, G. Kokogiannakis, Z. Ma, P. Cooper, Development of a dynamic model for a hybrid photovoltaic thermal collector-Solar air heater with fins, Renewable Energy, 101 (2017) 816-834.

[30] S. Churchill, M. Bernstein, A correlating equation for forced convection from gases and liquids to a circular cylinder in crossflow, Journal of Heat Transfer, 99 (2) (1977) 300-306.

[31] H. Hussein, M. Mohamad, A. El-Asfouri, Optimization of a wickless heat pipe flat plate solar collector, Energy Conversion and Management, 40 (18) (1999) 1949-1961.

[32] D. Thevenard, Updating the ASHRAE climatic data for design and standards (RP-1453), American Society of Heating Refrigeration and Air-Conditioning Engineers, Atlanta, GA, (2009).

[33] H. Zondag, D. De Vries, W. Van Helden, R. Van Zolingen, A. Van Steenhoven, The yield of different combined PVthermal collector designs, Solar energy, 74 (3) (2003) 253-269.

[34] R. Karwa, S. Solanki, J. Saini, Thermo-hydraulic performance of solar air heaters having integral chamfered rib roughness on absorber plates, Energy, 26 (2) (2001) 161-176.

[35] A.A. Hegazy, Thermohydraulic performance of air heating solar collectors with variable width, flat absorber plates, Energy conversion and management, 41 (13) (2000) 1361-1378.

[36] M. Ramadan, A. El-Sebaii, S. Aboul-Enein, E. El-Bialy, Thermal performance of a packed bed double-pass solar air heater, Energy, 32 (8) (2007) 1524-1535.

[37] B.R. Munson, D.F. Young, T.H. Okiishi, Fundamentals of fluid mechanics, New York, 3 (4) (1990).

[38] T.L. Bergman, F.P. Incropera, Fundamentals of heat and mass transfer, John Wiley \& Sons, 2011.

[39] J.A. Duffie, W.A. Beckman, Solar engineering of thermal processes, John Wiley \& Sons, 2013.

[40] A. Shirazi, R.A. Taylor, G.L. Morrison, S.D. White, A comprehensive, multi-objective optimization of solar-powered absorption chiller systems for air-conditioning applications, Energy Conversion and Management, 132 (2017) $281-306$.

[41] A. Polman, M. Knight, E.C. Garnett, B. Ehrler, W.C. Sinke, Photovoltaic materials: Present efficiencies and future challenges, Science, 352 (6283) (2016).

[42] getquote, 2017. www.getquote.com.au. (Accessed 10 Nov 2017).

[43] SteelBuilders, 2017. https://www.steelbuilders.com.au. (Accessed 15 Sep 2017).

[44] Alibaba, 2017. www.alibaba.com. (Accessed 10 Nov 2017).

[45] SolarChoice, 2017. https://www.solarchoice.net.au/. (Accessed 8 Oct 2017).

[46] Bunnings, 2017. https://www.bunnings.com.au. (Accessed 9 Oct 2017).

[47] dodo, 2017. offers.dodo.com. (Accessed 9 Oct 2017).

[48] C. Ho, H. Yeh, R. Wang, Heat-transfer enhancement in double-pass flat-plate solar air heaters with recycle, Energy, 30 (15) (2005) 2796-2817. 
